\title{
The Basolateral Amygdala Is Critical for Learning about Neutral Stimuli in the Presence of Danger, and the Perirhinal Cortex Is Critical in the Absence of Danger
}

\author{
Nathan M. Holmes, ${ }^{1}$ Shauna L. Parkes, ${ }^{2}$ A. Simon Killcross, ${ }^{1}$ and R. Frederick Westbrook ${ }^{1}$ \\ ${ }^{1}$ School of Psychology, University of New South Wales, Sydney 2052, New South Wales, Australia, and ${ }^{2}$ Brain and Mind Research Institute, University of \\ Sydney, Camperdown 2050, New South Wales, Australia
}

\begin{abstract}
The perirhinal cortex (PRh) and basolateral amygdala (BLA) appear to mediate distinct aspects of learning and memory. Here, we used rats to investigate the involvement of the PRh and BLA in acquisition and extinction of associations between two different environmental stimuli (e.g., a tone and a light) in higher-order conditioning. When both stimuli were neutral, infusion of the $\mathrm{GABA}_{\mathrm{A}}$, muscimol, or the NMDA receptor (NMDAR) antagonist ifenprodil into the PRh impaired associative formation. However, when one stimulus was neutral and the other was a learned danger signal, acquisition and extinction of the association between them was unaffected by manipulations targeting the PRh. Temporary inactivation of the BLA had the opposite effect: formation and extinction of an association between two stimuli was spared when both stimuli were neutral, but impaired when one stimulus was a learned danger signal. Subsequent experiments showed that the experience of fear per se shifts processing of an association between neutral stimuli from the PRh to the BLA. When training was conducted in a dangerous environment, formation and extinction of an association between neutral stimuli was impaired by BLA inactivation or NMDAR blockade in this region, but was unaffected by PRh inactivation. These double dissociations in the roles of the $\mathrm{PRh}$ and BLA in learning under different stimulus and environmental conditions imply that fear-induced activation of the amygdala changes how the brain processes sensory stimuli. Harmless stimuli are treated as potentially harmful, resulting in a shift from cortical to subcortical processing in the BLA.
\end{abstract}

\section{Introduction}

Fear conditioning in laboratory rats is widely used to study how neutral stimuli acquire motivational value. In one protocol, rats exposed to pairings of a tone and shock exhibit fear when subsequently tested with the tone. These fear responses extinguish when the tone is repeatedly presented in the absence of shock. Both forms of learning critically depend on the amygdala, specifically its basolateral nucleus [i.e., basolateral amygdale (BLA)]: BLA infusion of the $\mathrm{GABA}_{\mathrm{A}}$ agonist muscimol (MUS) or the NMDA receptor (NMDAR) antagonist ifenprodil (IFEN) impairs both the acquisition and extinction of so-called first-order fear to the tone (Wilensky et al., 1999; Rodrigues et al., 2001; Sotres-Bayon et al., 2007; Herry et al., 2008). Rats also learn associations between neutral stimuli and learned danger signals (e.g., the tone). Pairings of a neutral light with the now dangerous tone result in fear of the light; this fear again extinguishes when

Received April 28, 2013; revised June 29, 2013; accepted July 2, 2013.

Author contributions: N.M.H., S.L.P., A.S.K., and R.F.W. designed research; N.M.H. performed research; N.M.H. analyzed data; N.M.H. and R.F.W. wrote the paper.

This research was supported by Australian Research Council Discovery Project Grant DP13013687 to R.F.W. and A.S.K. The authors thank Belinda Lay and Neda Assareh for assistance with histology and scoring; Dominic Tran for assistance with the figures; and Kelly Clemens for comments on this and previous versions of the manuscript.

The authors declare no competing financial interests.

Correspondence should be addressed to R. Frederick Westbrook, School of Psychology, University of New South Wales, Sydney 2052, NSW, Australia. E-mail: f.westbrook@unsw.edu.au.

DOI:10.1523/JNEUROSCI.1998-13.2013

Copyright $\odot 2013$ the authors $\quad 0270-6474 / 13 / 3313112-14 \$ 15.00 / 0$ the light is repeatedly presented in the absence of its tone associate. The BLA is also critical for both forms of learning about the light. Temporary inactivation of the BLA or disruption of NMDAR transmission in the BLA impairs both the acquisition and extinction of so-called second-order fear of the light (Gewirtz and Davis, 1997; Parkes and Westbrook, 2010).

Rats also form associations between two neutral stimuli. Here, the association that results from paired presentations of a neutral light and a neutral tone is revealed once the tone is paired with shock: as a consequence of the tone-shock pairing, the light elicits fear. This association can also be broken through presentations of the neutral light in the absence of its neutral tone associate. However, in contrast to the acquisition and extinction of associations involving either innate (first-order) or learned (second-order) sources of danger, the BLA is not required for the acquisition or extinction of an association between a neutral light and a neutral tone (Parkes and Westbrook, 2010). Some evidence suggests that the perirhinal cortex $(\mathrm{PRh})$ may mediate formation of this association: rats with pretraining $\mathrm{PRh}$ lesions are impaired in the expression of fear to the light after conditioning of the tone (Nicholson and Freeman, 2000). However, the use of permanent lesions in this study leaves open the possibility that the formation of an association between neutral stimuli is coded elsewhere in the brain and that the $\mathrm{PRh}$ is simply required for its retrieval during testing.

The present study had two aims. The first was to identify the brain region that supports the formation and extinction of an 
association between a neutral light and a neutral tone. The second aim was to determine whether the brain region that codes the association between the light and the tone is determined by the emotional state of the rat. We show here that the formation and extinction of an association between two neutral stimuli requires the $\mathrm{PRh}$, not the BLA, but only when rats are not afraid; the formation and extinction of this association requires the BLA, not the PRh, when rats are afraid.

\section{Materials and Methods}

Subjects. Subjects were experimentally naive, male, outbred Wistar rats (280-350 g) obtained from a commercial supplier (Animal Resources Centre). They were housed in plastic boxes $(67 \mathrm{~cm}$ length $\times 40 \mathrm{~cm}$ width $\times 22 \mathrm{~cm}$ height) with food and water continuously available. There were eight rats per box. The boxes were located in a climate-controlled colony room (lights on at 7:00 A.M.). All experimental procedures were approved by the Animal Care and Ethics Committee at the University of New South Wales and in accordance with the National Institutes of Health Guidelines for the Care and Use of Laboratory Animals (revised 1996).

Surgery and drug infusions. Before behavioral testing, rats were implanted with guide cannulae directed toward the BLA or PRh. Rats were injected intraperitoneally with $1.3 \mathrm{ml} / \mathrm{kg}$ ketamine, an anesthetic (Ketapex; Apex Laboratories), at a concentration of $100 \mathrm{mg} / \mathrm{ml}$ and $0.3 \mathrm{ml} / \mathrm{kg}$ xylazine, a muscle relaxant (Rompun; Bayer), at a concentration of $20 \mathrm{mg} / \mathrm{ml}$. Anesthetized rats were then mounted on a stereotaxic apparatus (David Kopf Instruments), and 26 gauge guide cannulae (Plastics One) were implanted through holes drilled in both hemispheres of the skull. The tips of the guide cannulae were aimed bilaterally at one of two sites: BLA (anteroposterior: $-2.6 \mathrm{~mm}$; mediolateral: $+4.9 \mathrm{~mm}$; dorsoventral: $-8.0 \mathrm{~mm}$ ); or PRh (anteroposterior: $-4.08 \mathrm{~mm}$; mediolateral: $+5.00 \mathrm{~mm}$; dorsoventral: -8.0 ; angled at $10^{\circ}$; Paxinos and Watson, 1997). The guide cannulae were maintained in position with dental cement, and dummy cannulae were kept in each guide at all times except during infusions. Immediately after the surgical procedure, rats were injected intraperitoneally with a prophylactic $(0.4 \mathrm{ml})$ dose of a $300 \mathrm{mg} / \mathrm{kg}$ solution of procaine penicillin. Rats were allowed $7 \mathrm{~d}$ to recover from surgery, during which time they were handled and weighed daily.

Muscimol, ifenprodil, or vehicle (VEH) was infused bilaterally into the BLA or PRh by inserting a 33 gauge internal cannula into the guide cannula. The internal cannula was connected to a $25 \mu \mathrm{l}$ glass syringe attached to an infusion pump (Harvard Apparatus) and was projected an additional $1 \mathrm{~mm}$ ventral to the tip of the guide cannula. A total volume of $0.3 \mu \mathrm{l}$ (BLA) or $0.5 \mu \mathrm{l}$ (PRh) was delivered to both sides at a rate of $0.1 \mu \mathrm{l} / \mathrm{min}$. The internal cannula remained in place for an additional 1 min after the infusions and was then removed. One day before infusions, the dummy cannula was removed, and the infusion pump was turned on for 3-5 min to familiarize the rats with the procedure and thereby minimize stress on the infusion day.

Drugs. The $\mathrm{GABA}_{\mathrm{A}}$ agonist muscimol (Sigma) was dissolved in nonpyrogenic saline $(0.9 \% \mathrm{w} / \mathrm{v})$ to obtain a final concentration of $1 \mu \mathrm{g} / \mu \mathrm{l}$. Nonpyrogenic saline was used as a vehicle for experiments studying the effects of muscimol. Ifenprodil, a selective antagonist that blocks the NR2B subunit of NMDAR (Sigma), was dissolved in a solution of $0.9 \%$ nonpyrogenic saline (w/v) containing $5 \%$ (2-hydrocypropryl)- $\beta$ cyclodextrin (Sigma) adjusted to $\mathrm{pH}$ 7. This latter solution was used as a vehicle for experiments studying the effects of ifenprodil. Ifenprodil was microinjected into the BLA or PRh at a final concentration of $3.33 \mu \mathrm{g} / \mu \mathrm{l}$. The intervals between drug administration and behavior were 20 and $15 \mathrm{~min}$, respectively, for muscimol and ifenprodil. These intervals were selected on the basis of previous experiments reported by Parkes and Westbrook (2010).

Histology. Subsequent to behavioral testing, subjects received a lethal dose of sodium pentobarbital. The brains were removed and sectioned coronally at $40 \mu \mathrm{m}$ through the BLA or PRh. Every second section was collected on a slide and stained with cresyl violet. The location of the cannula tip was determined under a microscope by a trained observer, unaware of the subject's group designations, using the boundaries defined by the atlas of Paxinos and Watson (1997). Subjects with inaccurate cannula placements or with extensive damage were excluded from the statistical analysis.

Behavioral apparatus. Training and testing took place in eight chambers. The side walls and ceiling of each chamber $(30 \mathrm{~cm}$ height $\times 27 \mathrm{~cm}$ length $\times 30 \mathrm{~cm}$ width) were made of aluminum, and the back and front walls were made of clear plastic. The side walls and ceiling were painted black. The floor was made of stainless steel rods, $2 \mathrm{~mm}$ in diameter, spaced $13 \mathrm{~mm}$ apart, center to center. A tray below the floor contained bedding material. Each chamber was enclosed in a sound- and lightattenuating shell. A white fluorescent tube and speaker mounted on the back wall of each shell were used, respectively, for the presentation of a light conditioned stimulus (CS; $\sim 57$ lux measured at the center of the chamber) flashing at a rate of $3.5 \mathrm{~Hz}$ and a $620 \mathrm{~Hz}$ square-wave tone CS measuring $70 \mathrm{~dB}$ (A scale) against a background noise of $\sim 45 \mathrm{~dB}$ measured by a digital sound level meter (Dick Smith Electronics). The physical identity of all CSs was fully counterbalanced. The levels of freezing to the CSs did not differ as a function of their physical identity in any experiment.

A custom-built constant-current shock generator, capable of delivering an unscrambled alternating current $50 \mathrm{~Hz}$ shock to the floor of each chamber, was used for the presentation of a $0.5 \mathrm{~s}$ duration shock at $0.8 \mathrm{~mA}$ intensity, unless specified otherwise. The floor of each chamber was cleaned with water after removal of each rat at the end of a session. Illumination for each chamber was provided by an infrared light source $(940 \pm 25 \mathrm{~nm})$. A camera mounted on the back wall of each shell recorded the behavior of each rat. Each camera was connected to a monitor and a DVD recorder located in another room of the laboratory. This room contained the computer that controlled stimulus presentations via the appropriate software (LabView; National Instruments).

Context exposure. On the first $2 \mathrm{~d}$ of each experiment, rats received two 30 min exposures to the conditioning chamber, separated by a minimum interval of $2 \mathrm{~h}$.

Sensory preconditioning. Sensory preconditioning involved eight presentations of the visual and auditory stimuli in a $1 \mathrm{~h}$ session. Five minutes after placement in the chamber, the stimulus designated as S2 was presented. The duration of each S2 presentation was $30 \mathrm{~s}$, whereas the duration of the stimulus designated as $\mathrm{S} 1$ was $10 \mathrm{~s}$. The offset of S2 cooccurred with the onset of $\mathrm{S} 1$ in groups receiving paired presentations, whereas S2 and S1 were presented separately for groups receiving unpaired presentations. The intertrial intervals (ITIs) were 6 and $3 \mathrm{~min}$, respectively, for paired and unpaired presentations. Rats remained in the conditioning chamber for $1 \mathrm{~min}$ following the final stimulus presentation.

Each first-order conditioning session involved two pairings of the $10 \mathrm{~s}$ $\mathrm{S} 1$ and the unconditioned stimulus (US; $0.5 \mathrm{~s}, 0.8 \mathrm{~mA}$ footshock). Five minutes after placement in the chamber, $\mathrm{S} 1$ was presented. The final $0.5 \mathrm{~s}$ of S1 overlapped with the US in groups receiving paired presentations, whereas S1 and the US were presented separately in groups receiving unpaired presentations. The average ITI between paired S1-US presentations was $12 \mathrm{~min}$, and $10 \mathrm{~min}$ for unpaired presentations. Rats remained in the chamber for $1 \mathrm{~min}$ following the final stimulus presentation. The interval between the two first-order conditioning sessions was $2 \mathrm{~h}$.

Context extinction. Twenty-four hours after first-order conditioning, rats received two 30 min context extinction sessions, one in the morning and the other in the afternoon. This was done to extinguish any freezing elicited by context and thereby to provide a measure of the freezing elicited by the CSs per se.

Second-order conditioning. Second-order conditioning consisted in four presentations each of S2 and S1. Five minutes after placement in the chamber, S2 was presented. The offset of the $30 \mathrm{~s} \mathrm{S2} \mathrm{co-occurred} \mathrm{with} \mathrm{the}$ onset of the $10 \mathrm{~s} S 1$ in paired groups. The ITI between the paired presentations was $5 \mathrm{~min}$. S2 and S1 were presented separately in unpaired groups. The average ITI between presentations was 6 min. Rats remained in the chamber for $1 \mathrm{~min}$ following the final stimulus presentation.

Sensory preconditioning extinction. Five minutes after placement in the chambers, rats received eight S2-alone presentations with an ITI of 3 $\mathrm{min}$. These $\mathrm{S} 2$-alone presentations occurred before $\mathrm{S} 1-\mathrm{US}$ pairings (Experiments 3 and 6), so-called pre-extinction (PE; Coppock, 1958), or after S1-US pairings conditioning (Experiments 4A and 4B). 
Table 1. Behavioral demonstration of sensory preconditioned fear

\begin{tabular}{lllll}
\hline & SPC & First-order & S2 test & S1 test \\
\hline Group PP & S2 - S1 & S1-US & S2- & S1- \\
Group PU & $S 2-S 1$ & S1/US & $S 2-$ & $S 1-$ \\
Group UP & $S 2 / S 1$ & $S 1-$ US & $S 2-$ & $S 1-$ \\
\hline
\end{tabular}

S1 and S2 were a tone and flashing light stimulus (counterbalanced), and the US was electric footshock. A minus sign $(-)$ between two events denotes that the events were paired; a virgule (/) denotes that the two events were explicitly unpaired; A minus sign $(-)$ following one event denotes that the event was presented alone (in the absence of shock).

Testing. Five minutes after placement in the chambers, rats received eight S2-alone presentations, and on the following day eight S1-alone presentations. The ITI was 3 min in each test session.

Data analysis. Freezing was used to assess conditioned fear. It was defined as the absence of all movement except those related to breathing (Fanselow, 1980). Each rat was observed every $2 \mathrm{~s}$ and scored as either "freezing" or "not freezing" by two observers, one of whom was naive to group allocation. A percentage score was calculated for the proportion of the total observations scored as freezing for each rat. There was a high degree of agreement between the two observers, with a Pearson product moment correlation $>0.90$. Any disagreement was resolved in favor of the score by the naive observer. Data were analyzed with a planned, orthogonal contrast procedure controlling the per contrast error rate (Hays, 1963). Significance was set at $\alpha=0.05$.

\section{Results}

\section{Experiment 1A: demonstration of sensory} preconditioned fear

The aim of Experiment 1A was to show that freezing to S2 on test was due to its pairing with the neutral S1 and to the subsequent pairings of S1 and the US. The design is shown in Table 1. On Days 1 and 2, all rats received twice-daily pre-exposure to the context. On Day 3, rats in Groups PP (paired-paired presentation) and PU (paired-unpaired presentation) were exposed to pairings of S2 and S1, whereas Group UP (unpaired-paired presentation) received unpaired presentations of S2 and S1. On Day 4, rats in Groups PP and UP were exposed to pairings of S1 and the US, while Group PU was exposed to unpaired presentations of $\mathrm{S} 1$ and the US. Freezing to the context was extinguished in two 30 min sessions on Day 5. All rats were tested with S2 on Day 6 and with $\mathrm{S} 1$ on Day 7.

One rat did not receive the shock during first-order conditioning and was excluded from the statistical analysis. Groups exposed to pairings of $\mathrm{S} 1$ and shock (PP and UP) did not differ in their levels of freezing to $S 1$ ( $F$ values $<1)$, but froze significantly more than Group PU, which received unpaired presentations of $S 1$ and $\operatorname{shock}\left(F_{(1,20)}=6.45 ; p=0.02\right)$. There was a linear increase in freezing across the four conditioning trials $\left(F_{(1,20)}=38.22\right.$; $p<0.05)$ but no significant linear $\times$ group interactions $\left(F_{(1,20)}\right.$ values $<1 ; p>0.05$ ).

Figure $1 A$, left, shows the mean ( \pm SEM) levels of freezing to $\mathrm{S} 2$ at test, averaged across the eight presentations. Group PP froze significantly more to S2 than Groups PU and UP $\left(F_{(1,20)}=7.71\right.$; $p<0.05)$, who did not differ from each other in their levels of freezing $\left(F_{(1,20)}<1.3 ; p>0.05\right)$. Figure $1 A$, right, shows the mean $( \pm$ SEM) levels of freezing to $S 1$ at test, averaged across the eight presentations. Groups PP and UP, which received S1-US pairings, did not differ from each other in their levels of freezing to $S 1$ $\left(F_{(1,20)}<1 ; p>0.05\right)$ but froze significantly more to S1 than the group that received unpaired presentations of $S 1$ and the US $\left(F_{(1,20)}=11.73 ; p<0.05\right)$.

These results show that freezing to S2 was contingent on its pairings with $\mathrm{S} 1$ and on the subsequent pairings of $\mathrm{S} 1$ and the US. Thus, freezing to S2 was due to its association with S1, rather than a generalization of freezing to S2 from S1, and to the association between $S 1$ and the US, rather than to any intrinsic ability of S1 to condition freezing to S2.

\section{Experiment 1B: the association between S2 and a neutral S1 requires the $\mathrm{PRh}$ but not the BLA}

Experiment $1 \mathrm{~B}$ examined the roles of the PRh and the BLA in coding the association between S2 and a neutral S1. Rats were implanted with bilateral cannulae targeting the PRh or BLA and were allowed $5 \mathrm{~d}$ for recovery. On Days 1 and 2, rats received twice-daily exposures to the chambers. On Day 3, rats in Groups PRh-MUS and BLA-MUS received an infusion of muscimol in the PRh or BLA, respectively, whereas those in Groups PRh-VEH and BLA-VEH were infused with VEH in the PRh and BLA, respectively. Twenty minutes later, all rats received eight paired presentations of S2 and S1. On Day 4, all rats received two S1-US pairings in the morning session and two pairings in the afternoon session. On Day 5, all rats received a context extinction session in the morning and another in the afternoon. On Days 6 and 7, rats were tested with S2 and S1, respectively.

\section{Histology}

Figure 2 shows the locations of injection cannulae tips for rats in this and the remaining experiments. Plotted points represent the ventral point of the cannula track. Five rats in Experiment $1 \mathrm{~B}$ were excluded due to misplaced cannulae, resulting in the following group sizes: Group PRh-VEH, $n=10$; Group PRh-MUS, $n=7$; Group BLA-VEH, $n=8$; and Group BLA-MUS, $n=8$.

\section{Behavior}

As there were no differences between PRh and BLA rats infused with saline at any stage of the experiment, the data for these rats were combined to form a single control group (Group VEH). There were no differences among the groups in acquisition of conditioned fear $\left(F_{(1,30)}\right.$ values $\left.<2.2 ; p>0.05\right)$. The mean $( \pm$ SEM) levels of freezing on the final S1 trial were $72 \pm 6.7 \%$ in Group VEH, $68 \pm 7.5 \%$ in Group PRh-MUS, and $68 \pm 6.3 \%$ in Group BLA-MUS. Figure $1 B$, left, shows the mean ( \pm SEM) levels of freezing to $\mathrm{S} 2$ at test, averaged across the eight presentations. The PRh was critical for the association between S2 and the neutral $\mathrm{S} 1$ as rats infused with muscimol into the PRh before the S2-S1 pairings froze significantly less to S2 than Groups VEH and BLA-MUS combined $\left(F_{(1,30)}=7.32 ; p<0.05\right)$. In contrast, the association between $\mathrm{S} 2$ and the neutral $\mathrm{S} 1$ did not require the BLA as there was just as much freezing to S2 among rats in Group BLA-MUS as in Group VEH $(F$ values $<1)$. Figure $1 B$, right, shows the mean $( \pm \mathrm{SEM})$ levels of freezing to $\mathrm{S} 1$ at test, averaged across the eight presentations. There were no significant differences between the groups $\left(F_{(1,30)}<1.9 ; p>0.05\right)$, showing that the deficit in sensory preconditioned freezing to $\mathrm{S} 2$ among rats in Group PRh-MUS was not due to impaired conditioning of S1.

Two additional groups were used to examine whether NMDAR transmission in the PRh was critical for the plasticity underlying the association between S2 and the neutral S1. The protocol was identical to that described except that S2-S1 pairings were conducted under a PRh infusion of IFEN (Group IFEN) or VEH (Group VEH). Seven rats were excluded due to misplaced cannulae, resulting in $n=14$ in each group.

Groups VEH and IFEN did not differ in the acquisition of conditioned fear $\left(F_{(1,26)}<2.4 ; p>0.05\right)$. The mean $( \pm$ SEM) levels of freezing on the final S1 trial were $57 \pm 8.9 \%$ in Group $\mathrm{VEH}$ and $53 \pm 6.9 \%$ in Group IFEN. Figure $1 C$ shows mean ( \pm SEM) test levels of freezing to S2, averaged across the eight 
A
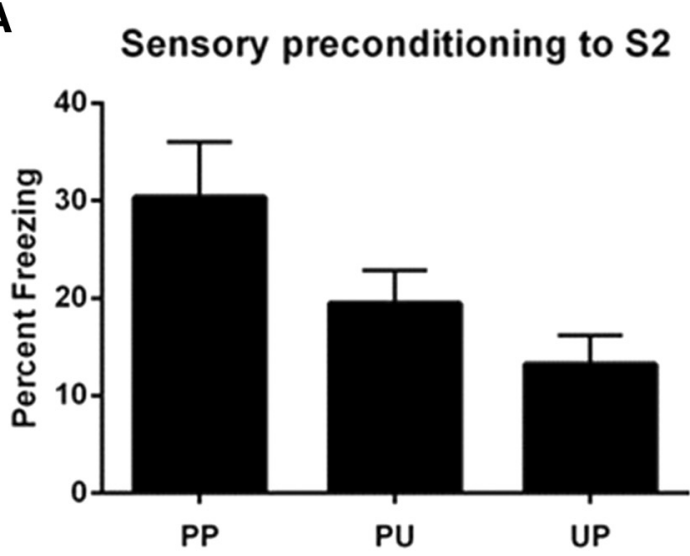

Group

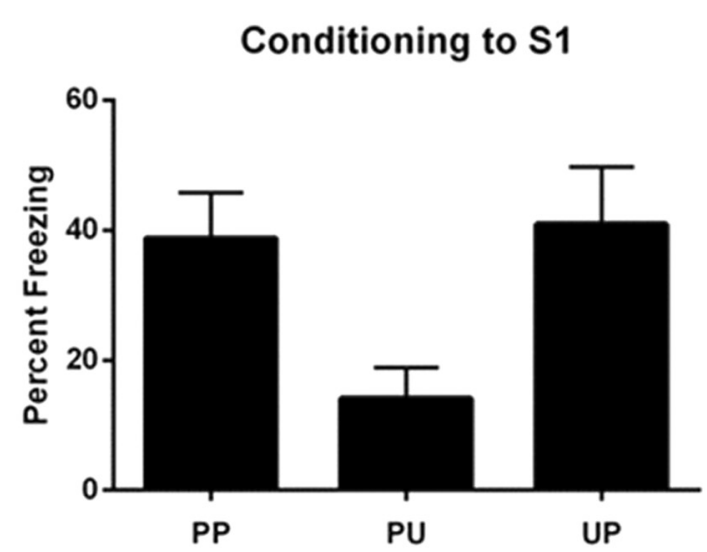

Group

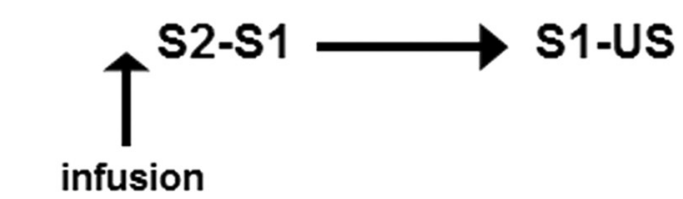

B

Sensory preconditioning to S2

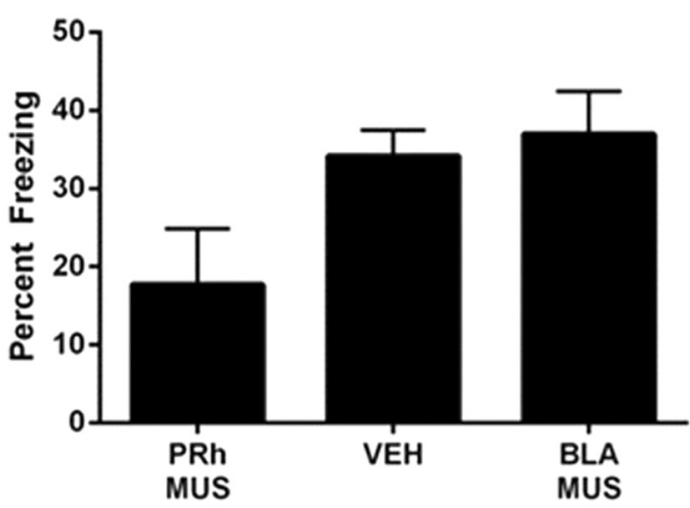

Group
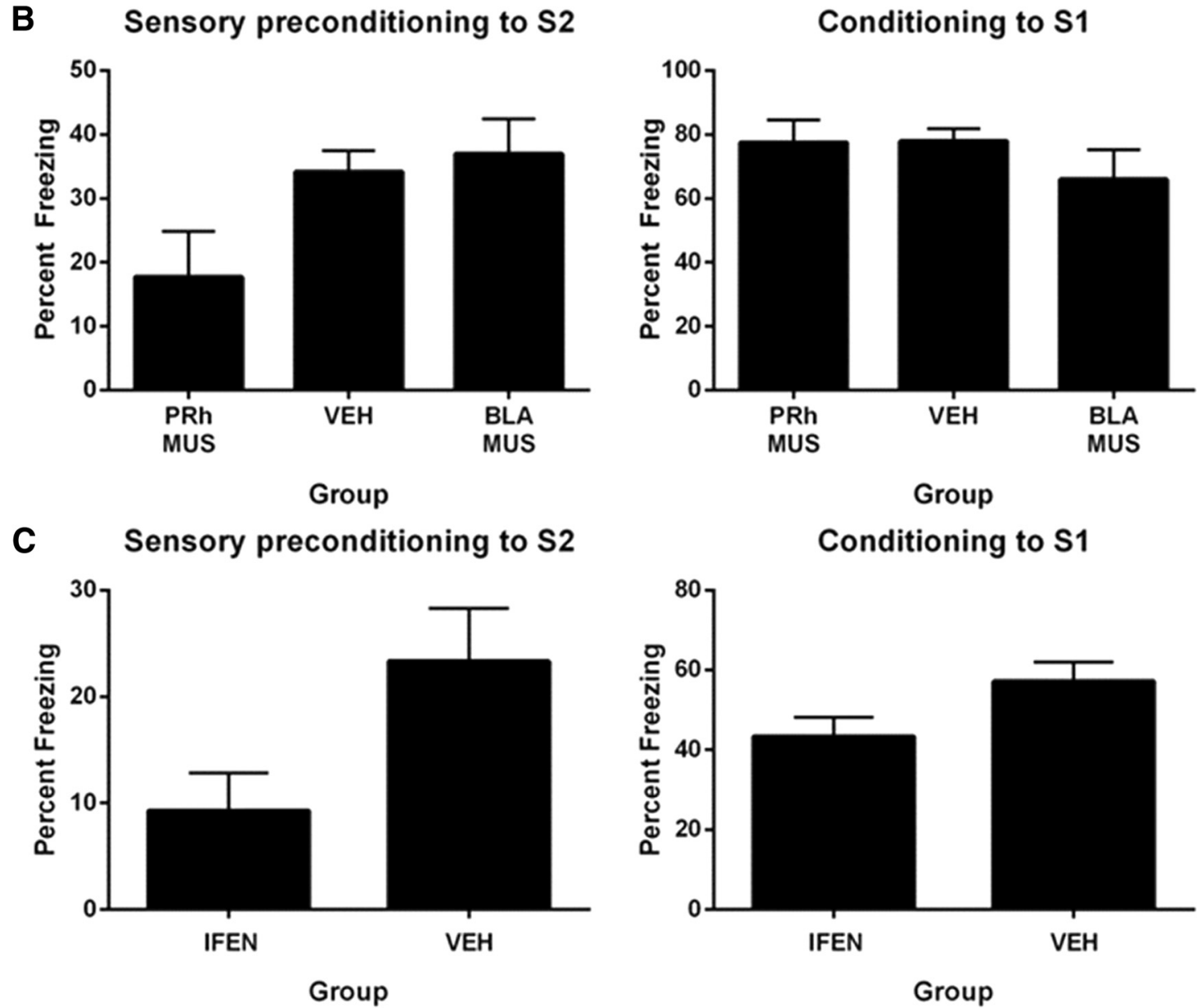

Group

Conditioning to $\mathrm{S1}$

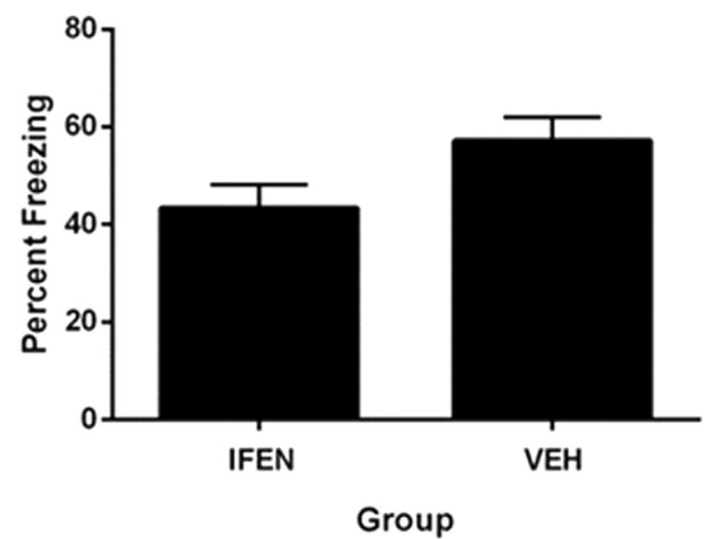

Figure 1. Sensory preconditioning of an association between $S 2$ and a neutral S1. $A$, Behavioral demonstration of sensory preconditioning (Experiment $1 \mathrm{~A}$ : Group PP, $n=7 ;$ Group PU, $n=8$; and Group UP, $n=8$ ). Left, Freezing to S2 during the test for sensory preconditioned fear. Right, Freezing to $S 1$ during the test for first-order conditioned fear. $\boldsymbol{B}$, The roles of the PRh and BLA in the acquisition of a sensory preconditioned association (Experiment 1B: Group PRh-VEH, $n=10$; Group PRh-MUS, $n=7$; Group BLA-VEH, $n=8 ;$ Group BLA-MUS, $n=8$ ). Left, Freezing to S2 during the test for sensory preconditioned fear. Right, Freezing to $\$ 1$ during the test for first-order conditioned fear. $C$, The involvement of PRh NMDAR in acquisition of a sensory preconditioned association (Experiment 1C: Group VEH, $n=14$; Group IFEN, $n=14$ ). Left, Freezing to S2 during the test for sensory preconditioned fear. Right, Freezing to S1 during the test for retention of first-order conditioned fear. Data shown are means \pm SEM. 


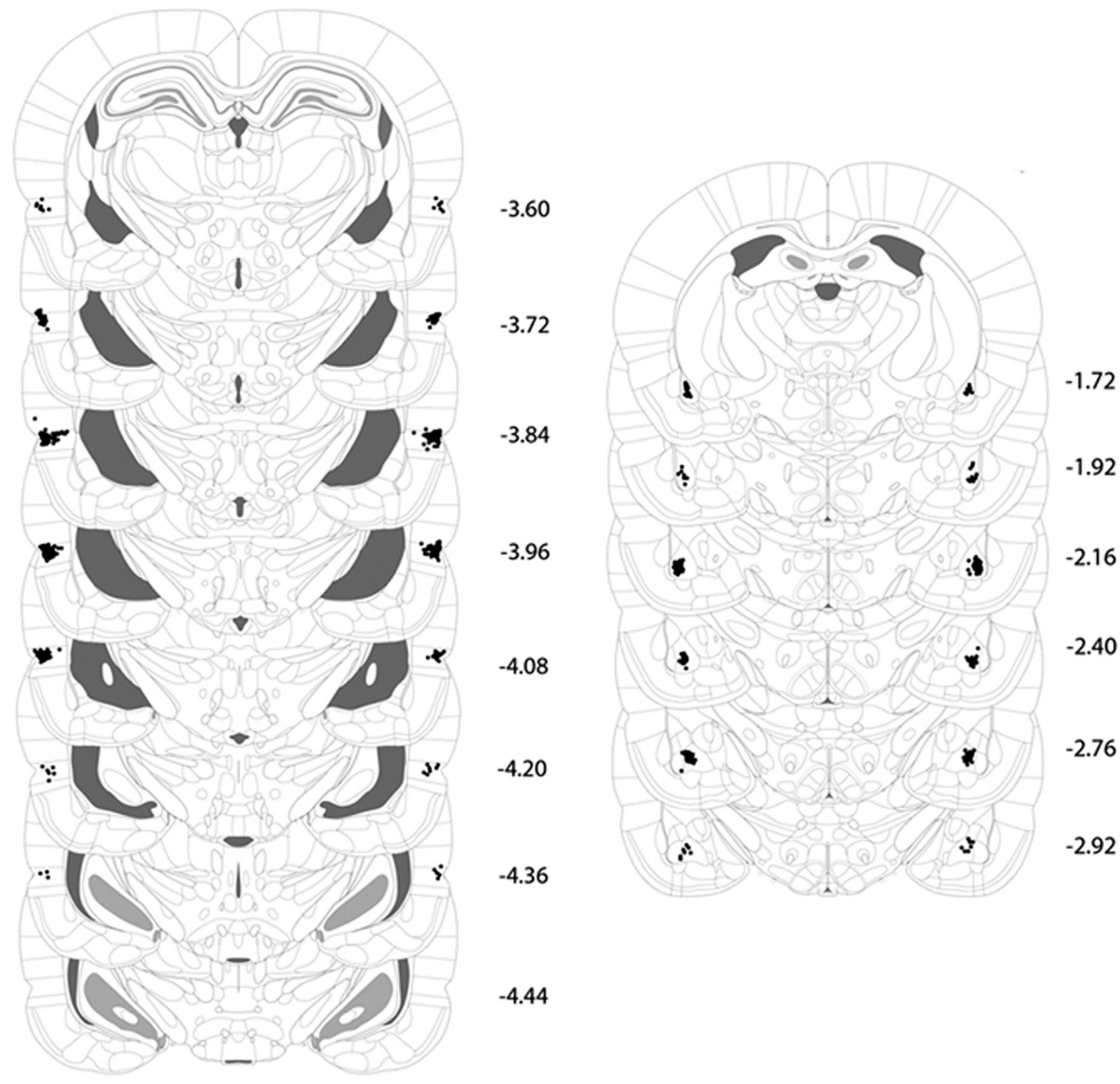

Figure 2. Microinfusion cannula placements as verified on Nissl-stained coronal sections for the PRh (left) and BLA (right). Sections are based on the atlas of Paxinos and Watson (1997).

presentations (Fig 1C, left), and $\mathrm{S} 1$, averaged across the eight presentations (Fig $1 C$, right). The association between $\mathrm{S} 2$ and the neutral S1 was impaired by an infusion of ifenprodil as Group IFEN froze significantly less when tested with S2 than Group $\operatorname{VEH}\left(F_{(1,26)}=5.15 ; p<0.05\right)$. The difference between the levels of freezing to $S 2$ was not due to differences in freezing to $S 1$ as rats in both groups exhibited substantial and similar $\left(F_{(1,26)}=3.97\right.$; $p>0.05$ ) levels of freezing to $S 1$.

\section{Experiment 2: extinction of the association between S2 and the neutral S1 requires neuronal activity, specifically, NMDAR neurotransmission in the PRh}

This experiment had two aims. The first was to show that S2alone presentations interpolated between S2-S1 pairings and S1-US pairings extinguish the association that mediates fear responses to S2. The second aim was to show that neuronal activity in the PRh, specifically NMDAR neurotransmission, is critical for extinction of the association between S2 and the neutral S1.

All rats were implanted with bilateral cannulae targeting the $\mathrm{PRh}$ and were allowed $5 \mathrm{~d}$ recovery. On Days 1 and 2, rats were exposed to the chambers. On Day 3, all rats received S2-S1 pairings, and on Day 4 three groups of rats were exposed to eight presentations of S2 alone. This so-called PE occurred under a PRh infusion of MUS (PE-MUS), IFEN (PE-IFEN), or VEH (saline for half the rats and saline plus cyclodextrin for the remainder; PE$\mathrm{VEH})$. A fourth group of rats (NO-PE) were exposed to the chambers but did not received S2-alone presentations. Equal numbers of rats in this group received a PRh infusion of muscimol, ifenprodil, or vehicle. On Day 5, all rats received S1-US pairings in the manner previously described, and on Day 6, two sessions of context extinction to reduce levels of freezing to the context alone. On Days 7 and 8 , rats were tested with $S 2$ and $S 1$, respectively.

\section{Histology}

Four rats were excluded due to a misplaced cannula, yielding the following group sizes: PE-MUS, $n=9$; PE-IFEN, $n=9$; PE-VEH, $n=9$; and NO-PE, $n=9$.

\section{Behavior}

First-order conditioning was successful. All rats learned to fear $\mathrm{S} 1$, and there were no significant differences among the groups in rate of acquisition $\left(F_{(1,32)}\right.$ values $\left.<1 ; p>0.05\right)$ or overall levels of freezing $\left(F_{(1,32)}\right.$ values $\left.<1 ; p>0.05\right)$. The mean ( \pm SEM) levels of freezing on the final S1 trial were $53 \pm 8.0 \%$ in Group PE-MUS, 


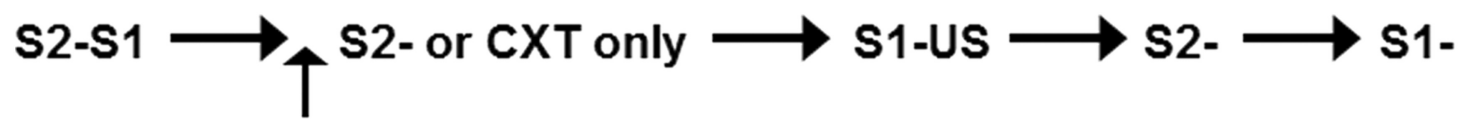

infusion

Sensory preconditioning to S2

\section{Conditioning to S1}
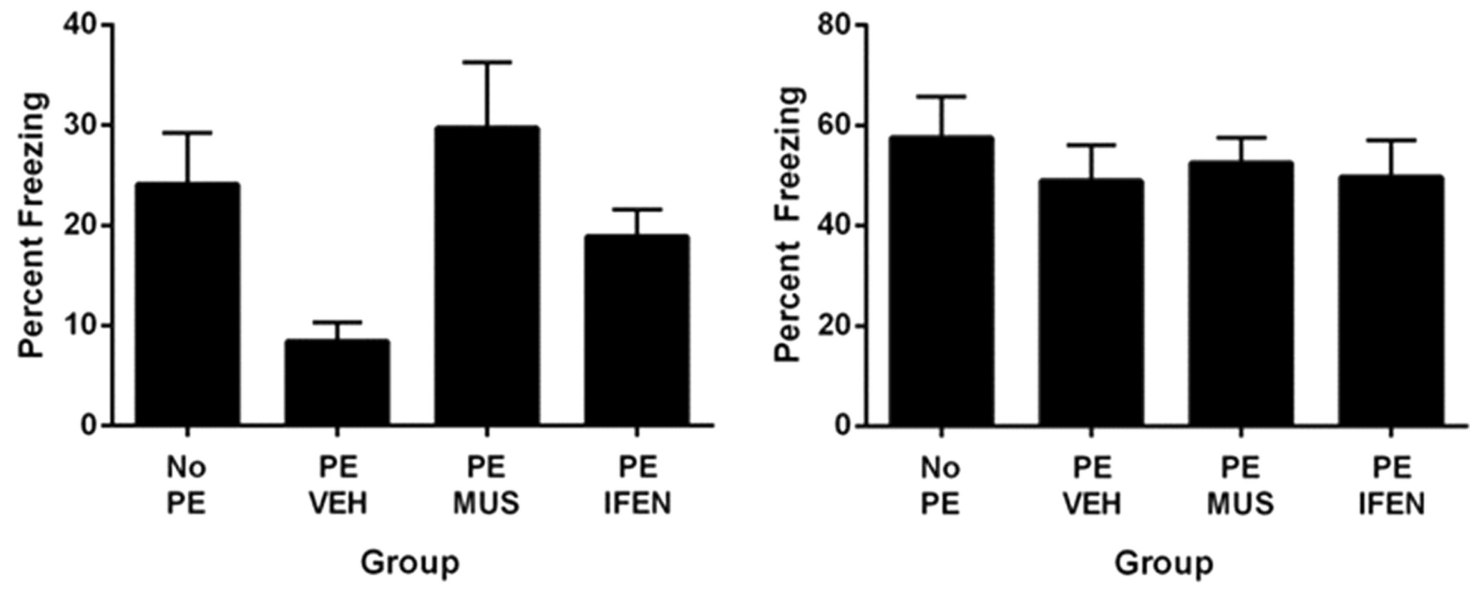

Figure 3. Pre-extinction of a sensory preconditioned association requires activation of the PRh and activation of NMDAR containing the NR2B subunit (Experiment 2: PE-MUS, $n=9 ; \mathrm{PE}-\mathrm{IFEN}, n=$ 9; PE-VEH, $n=9 ; \mathrm{NO}-\mathrm{PE}, n=9$ ). Left, Freezing to $\mathrm{S2}$ during the test for pre-extinction of a sensory preconditioned association. Right, Freezing to $\mathrm{S} 1$ during the test for retention of first-order conditioned fear. Data shown are means \pm SEM.

$53 \pm 8.0 \%$ in Group PE-IFEN, $60 \pm 7.0 \%$ in Group PE-VEH, and $62 \pm 9.0 \%$ in Group NO-PE.

Figure 3 shows the test levels of freezing (mean \pm SEM) to S2 (Fig. 3, left) and S1 (Fig. 3, right). S2-alone presentations extinguished its association with $\mathrm{S} 1$ as Group PE-VEH froze significantly less to $\mathrm{S} 2$ than the other three groups combined $\left(F_{(1,32)}=9.24 ; p<0.05\right)$. There were no statistically significant differences between the levels of freezing to $S 2$ in the group that was not extinguished to S2 (NO-PE) and the groups extinguished under muscimol or ifenprodil $(F$ values $<1)$, showing that inactivation of the PRh or disruption of NMDAR neurotransmission in the PRh impaired extinction of the association between S2 and the neutral S1. There were no statistically significant differences between the levels of freezing to S2 in groups PE-MUS and PEIFEN $\left(F_{(1,32)}=2.9 ; p>0.05\right)$, indicating that extinction of the S2-S1 association had been equally impaired by these treatments. None of the differences in freezing to $\mathrm{S} 2$ were due to variations in conditioning to $\mathrm{S} 1$; freezing to $\mathrm{S} 1$ was substantial, and there were no statistically significant differences among the groups $\left(F_{(1,32)}\right.$ values $<1 ; p>0.05)$. These results show that NMDAR neurotransmission in the $\mathrm{PRh}$ is critical for extinction of the association between $\mathrm{S} 2$ and the neutral S1, while previous results have shown that neuronal activity in the BLA is not required for extinction of this association (Parkes and Westbrook, 2010; Experiment 6).

Experiment 3A: demonstration of second-order conditioned fear

The aim of this experiment was to show that second-order conditioned fear was due to S1-US and S2-S1 pairings. The design is shown in Table 2. On Days 1 and 2, rats were exposed to the chambers. On Day 3, rats in Groups PP and PU received S1-US pairings, whereas Group PU was exposed to unpaired presentations of S1 and the US. On Day 4, freezing to the context was extinguished in two 30 min sessions, one in the morning and the other in the afternoon. On Day 5, Groups PP and UP were ex-
Table 2. Behavioral demonstration of second-order conditioned fear

\begin{tabular}{lllll}
\hline & First-order & Second-order & S2 test & S1 test \\
\hline Group PP & S1- US & S2 - S1 & S2- & S1- \\
Group PU & S1- US & S2/S1 & S2- & S1- \\
Group UP & S1/US & $S 2-S 1$ & $S 2-$ & S1- \\
\hline
\end{tabular}

S1 and S2 were a tone and flashing light stimulus (counterbalanced), and the US was electric footshock. A minus sign (-) between two events denotes that the events were paired; a virgule (/) denotes that the two events were explicitly unpaired; a minus sign (-) following one event denotes that the event was presented alone (in the absence of shock).

posed to pairings of S2 and S1, whereas Group UP received unpaired presentations of S2 and S1. All rats received two sessions (morning and afternoon) of context extinction on Day 6, and were then tested for freezing to S2 on Day 7, and to S1 on Day 8.

First-order conditioning was successful. Rats in Groups PP and PU froze more to S1 than those in Group UP $\left(F_{(1,21)}=17.24\right.$ $p<0.05)$ but did not differ from each other $\left(F_{(1,21)}=3.06\right.$; $p>0.05)$. The mean ( \pm SEM) level of freezing on the final $S 1$ trial was $50 \pm 8 \%$ in Group PP, $51 \pm 10 \%$ ) in Group PU, and $18 \pm 8 \%$ in Group UP. Second-order conditioning was also successful in that rats in Group PP froze significantly more to S2 across its pairings with S1 than those in Groups PU and UP $\left(F_{(1,21)}=11.42\right.$; $p<0.05)$, who did not differ from each other $(F$ values $<1)$. Firstorder conditioned freezing remained intact across the second-order conditioning stage: rats in Groups PP and PU did not differ in their levels of freezing to S1 ( $F$ values $<1$ ) but froze significantly more to S1 than those in Group UP $\left(F_{(1,21)}=70.97 ; p<0.05\right)$.

Figure $4 A$ shows the test levels of freezing (mean \pm SEM) to S2 (Fig 4A, left) and S1 (Fig 4A, right). Group PP froze significantly more to S2 than Groups PU and UP $\left(F_{(1,21)}=45.25 ; p<0.05\right)$, who did not differ from each other in their levels of freezing $\left(F_{(1,21)}=4.5 ; p>0.05\right)$, showing that freezing to $\mathrm{S} 2$ was due to its pairing with $S 1$ and to the prior pairings of $S 1$ with the US. Groups PP and PU did not differ from each other in their levels of freezing to $\mathrm{S} 1\left(F_{(1,21)}<1.4 ; p>0.05\right)$ but froze significantly more to $S 1$ than Group UP, who received unpaired presentations of S1 
A

$2^{\text {nd }}$-order conditioning to S2

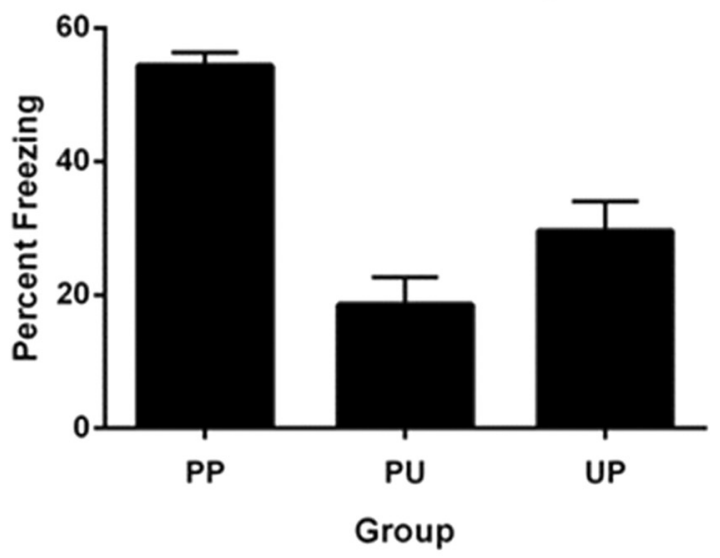

$1^{\text {st }}$-order conditioning to $\mathrm{S} 1$

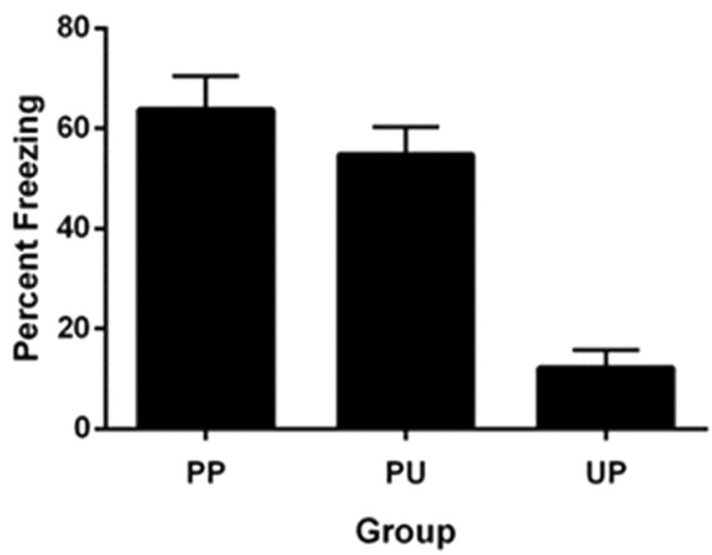

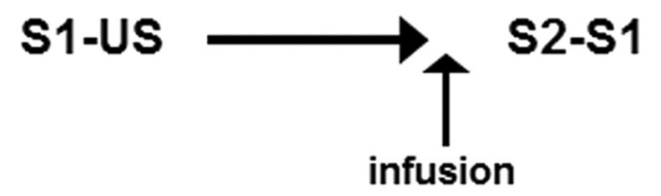

B $2^{\text {nd }}$-order conditioning to $\mathrm{S} 2$

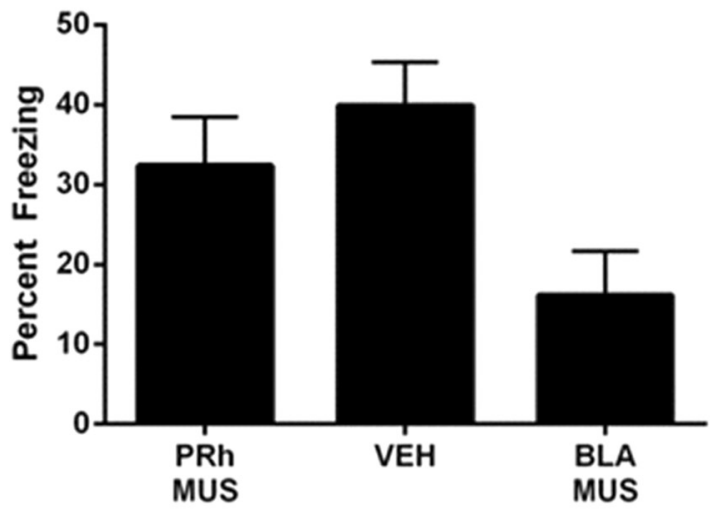

Group

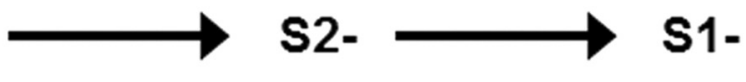

$1^{\text {st }}$-order conditioning to $\mathrm{S} 1$

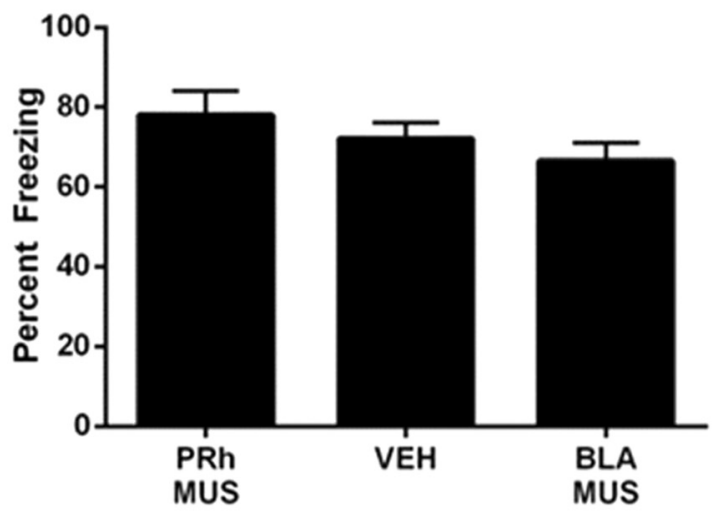

Group

Figure 4. Second-order conditioning of an association between $\mathrm{S} 2$ and a dangerous $\mathrm{S1}$. $A$, Behavioral demonstration of second-order conditioned fear (Experiment $3 \mathrm{~A}:$ Group PP, $n=8 ;$ Group $\mathrm{PU}, n=8$; Group UP, $n=8$ ). Left, Freezing to S2 during the test for second-order fear. Right, Freezing to S1 during the test for first-order conditioned fear. $\boldsymbol{B}$, The roles of the PRh and BLA in acquisition of second-order conditioned fear (Experiment 3B: Group PRh-VEH, $n=8$; Group PRh-MUS, $n=9$; Group BLA-VEH, $n=8$; Group BLA-MUS, $n=8$ ). Left, Freezing to S2 during the test for second-order fear. Right, Freezing to $\mathrm{S} 1$ during the test for first-order conditioned fear. Data shown are means \pm SEM.

and the US $\left(F_{(1,21)}=49.19 ; p<0.05\right)$, confirming that first conditioning was intact and that generalization of freezing from S1 to S2 was negligible in Group PU.

Experiment 3B: the association between $\mathrm{S} 2$ and the conditioned $S 1$ requires the BLA but not the PRh Experiment $3 \mathrm{~B}$ examined the roles of the PRh and the BLA in coding the association between S2 and the conditioned S1. Half of the rats in this experiment were implanted with bilateral cannulae targeting the PRh, while the remaining rats were implanted with bilateral cannulae targeting the BLA. Rats were allowed $5 \mathrm{~d}$ of recovery. All rats then received context familiarization (Days 1 and 2), first-order conditioning of S1 (Day 3), and context extinction (Day 4) in the manner described for Group PP in Experiment 3A. On Day 5, rats in Groups PRh-MUS and BLA-MUS received an infusion of muscimol, whereas rats in Groups PRh-
$\mathrm{VEH}$ and BLA-VEH were infused with vehicle. Twenty minutes later, all rats received eight paired presentations of S2 and the first-order conditioned S1. On Day 6, rats received two sessions of context extinction. Rats were then tested with S2 on Day 7 and $\mathrm{S} 1$ on Day 8 in the manner described previously.

\section{Histology}

Eight rats were excluded from Experiment 3B due to misplaced cannulae. This resulted in the following group sizes: Group PRhVEH, $n=8$; Group PRh-MUS, $n=9$; Group BLA-VEH, $n=8$; and Group BLA-MUS, $n=8$.

\section{Behavior}

As there were no differences between PRh and BLA rats infused with saline at any stage of the experiment, the data for these rats were combined to form a single control group (Group VEH). 
First-order conditioning was successful. All rats froze to S1, and there were no significant differences among the groups in overall levels of freezing to $S 1\left(F_{(1,30)}\right.$ values $\left.<2.25 ; p>0.05\right)$ or in the rate of its acquisition $\left(F_{(1,30)}\right.$ values $\left.<2.44 ; p>0.05\right)$. The mean $( \pm$ SEM) levels of freezing on the final S1 trial were $70 \pm 6 \%$ in Group VEH, $65 \pm 7 \%$ in Group BLA-MUS, and $75 \pm 5 \%$ in Group PRh-MUS. During second-order conditioning, infusion of muscimol into PRh and BLA depressed the freezing response: Group VEH froze significantly more to S2 and S1 than Groups PRh-MUS and BLA-MUS $\left(F_{(1,30)}<23.11 ; p<0.05\right)$. There were no differences in freezing between the latter groups $\left(F_{(1,30)}<1.07 ; p<0.05\right)$.

Figure $4 B$ shows the test levels of freezing (mean \pm SEM) to S2 (Fig. $4 B$, left) and S1 (Fig. 4B, right). Rats exposed to pairings of S2 and the conditioned S1 under vehicle or a PRh infusion of muscimol did not differ in their levels of freezing to S2 ( $F$ values $<1$ ), showing that the formation of this association was not dependent on the PRh. However, the levels of freezing to S2 in the vehicle- and PRh-infused groups were significantly greater than those exhibited by rats that received the pairings under a BLA infusion of muscimol $\left(F_{(1,30)}<6.25 ; p<0.05\right)$, showing that formation of the association between S2 and the fear-eliciting S1 was dependent on the BLA. Although muscimol infusion into both the PRh and BLA depressed freezing across the S2-S1 pairings, there were no long-term effects on freezing to $S 1$ as there were no significant differences between muscimol- and vehicleinfused groups in the test levels of freezing to $S 1\left(F_{(1,30)}\right.$ values $<1.61 ; p>0.05$ ).

Together with the previous findings, these results show that the roles of the PRh and BLA in the formation of an association between S2 and S1 are doubly dissociable depending on the value of S1: the PRh supports associative formation when S1 is neutral but not when it has been conditioned; and the BLA supports associative formation when $\mathrm{S} 1$ has been conditioned but not when it is neutral.

\section{Experiment 4A: extinction of sensory preconditioned fear does not require the $P R h$ or NMDAR neurotransmission in the PRh}

Neuronal activity, specifically NMDAR neurotransmission, in the PRh was critical for the extinction of the association between S2 and the neutral S1. The present experiment examined the role of the PRh in extinction of the fear elicited by S2. All rats were implanted with cannulae in the $\mathrm{PRh}$. After recovery and familiarization with the chambers (Days 1 and 2), all rats received S2-S1 pairings on Day 3 and S1-US pairings on Day 4, and two sessions of context extinction (morning and afternoon) on Day 5. On Day 6, three groups of rats were exposed to eight presentations of S2 alone. Before this session, rats received a PRh infusion of muscimol (Group EXT-MUS), ifenprodil (Group EXT-IFEN), or vehicle (saline for half the rats and saline plus cyclodextrin for the remainder; Group EXT-VEH). A fourth group of rats, Group NO-EXT, were exposed to the chambers but did not receive S2-alone presentations. Rats in Group NO-EXT received an infusion of muscimol, ifenprodil, or vehicle. On Days 6 and 7, rats were tested with S2 and S1, respectively, in the manner described previously.

\section{Histology}

One rat was excluded from Experiment 4A due to a misplaced cannula, yielding the following group sizes: EXT-MUS, $n=8$; EXT-IFEN, $n=8$; EXT-VEH, $n=8$; and NO- EXT, $n=7$.

\section{Behavior}

First-order conditioning was successful. All rats learned to fear $\mathrm{S} 1$, and there were no differences among the groups in the overall levels of freezing to $S 1\left(F_{(1,27)}\right.$ values $\left.<1 ; p>0.05\right)$ or in the rate at which freezing was acquired $\left(F_{(1,27)}\right.$ values $\left.<1 ; p>0.05\right)$. The mean $( \pm$ SEM) levels of freezing on the final S1-US trial were $68 \pm 8 \%$ in Group EXT-VEH, $63 \pm 10 \%$ in Group EXT-MUS, $65 \pm 9 \%$ in Group EXT-IFEN, and $60 \pm 8 \%$ in Group NO-EXT. During the extinction of sensory preconditioned fear, the freezing elicited by S2 declined linearly across the S2-alone presentations $\left(F_{(1,21)}=12.63 ; p<0.05\right)$. The PRh infusion of muscimol depressed freezing to $\mathrm{S} 2$, as rats in Group EXT-MUS froze significantly less often than those in Groups EXT-VEH and EXT-IFEN $\left(F_{(1,21)}=14.24 ; p<0.05\right)$, who did not differ from each other $\left(F_{(1,21)}<1 ; p>0.05\right)$. The linear $\times$ group interactions were not significant (largest: $\left.F_{(1,21)}=2.42 ; p>0.05\right)$.

Figure $5 A$ shows test levels of freezing (mean \pm SEM) to S2 (Fig. 5, left) and S1 (Fig. 5, right). Rats that did not receive the S2-alone presentations (Group NO-EXT) froze significantly more to $\mathrm{S} 2$ than the other three groups that received these presentations $\left(F_{(1,27)}=8.44 ; p<0.05\right)$. Group EXT-VEH did not differ in their levels of freezing to S2 compared with Groups EXT-MUS and EXT-IFEN combined $\left(F_{(1,27)}<1\right)$, and freezing to $\mathrm{S} 2$ did not differ between the latter groups $\left(F_{(1,27)}<1.67 ; p>\right.$ $0.05)$, showing that extinction had not been impaired by temporary inactivation of the $\mathrm{PRh}$ or by disruption of NMDA neurotransmission in this region. Infusion of muscimol or ifenprodil before extinction of S2 had no effect on retention of first-order conditioned fear as there were no statistically significant differences among the groups in the test levels of freezing to $S 1\left(F_{(1,27)}\right.$ values $<1.08$; $p>0.05$ ).

\section{Experiment 4B: extinction of sensory preconditioned fear requires the BLA and NMDAR neurotransmission in the BLA} The aim of this experiment was to show that the extinction of the fear elicited by the sensory preconditioned S2 was dependent on neuronal activity in the BLA, specifically NMDAR neurotransmission. All rats were implanted with bilateral cannulae targeting the BLA and were allowed $5 \mathrm{~d}$ of recovery. The procedure was identical to that in the previous experiment. Rats were familiarized with the chamber on Days 1 and 2; were exposed to S2-S1 pairings on Day 3, and first-order conditioning of S1 on Day 4; and were subjected to extinction of context-conditioned freezing on Day 5. On Day 6, rats received a BLA infusion of muscimol (EXT-MUS), ifenprodil (EXT-IFEN), or vehicle (EXT-VEH) followed 20 min later by S2-alone presentations. Rats in Group NO-EXT were infused with muscimol, ifenprodil, or vehicle into the BLA 20 min before exposure to the context alone. On Days 7 and 8 , rats were tested with S2 and S1, respectively, in the manner described previously.

\section{Histology}

Two rats were excluded due to misplaced cannulae yielding the following group sizes: EXT-MUS, $n=8$; EXT-IFEN, $n=8$; EXT$\mathrm{VEH}, n=9$; and NO-EXT, $n=9$.

\section{Behavior}

First-order conditioning was successful. The rate of acquisition of freezing responses across S1-US pairings did not differ between groups $\left(F_{(1,30)}\right.$ values $\left.<1 ; p>0.05\right)$. The mean $( \pm$ SEM) levels of freezing on the final S1-US trial were $58 \pm 9 \%$ in Group EXT$\mathrm{VEH}, 55 \pm 8 \%$ in Group EXT-MUS, $53 \pm 6 \%$ in Group EXTIFEN, and $62 \pm 10 \%$ in Group NO-EXT. Sensory preconditioned freezing declined linearly across the S2-alone presentations $\left(F_{(1,21)}=12.63 ; p<0.05\right)$. Muscimol in the BLA depressed freezing, as rats in Group EXT-MUS froze less to S2 than those in 


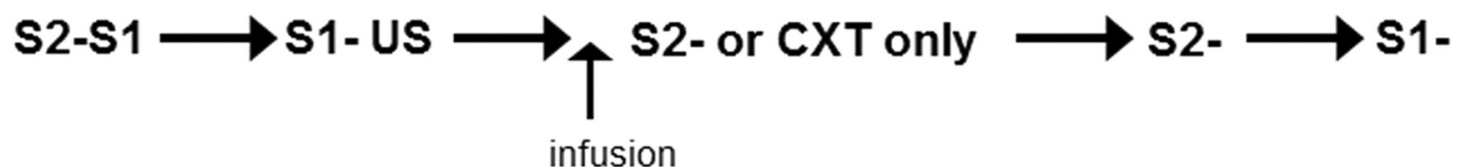

A

PRh:
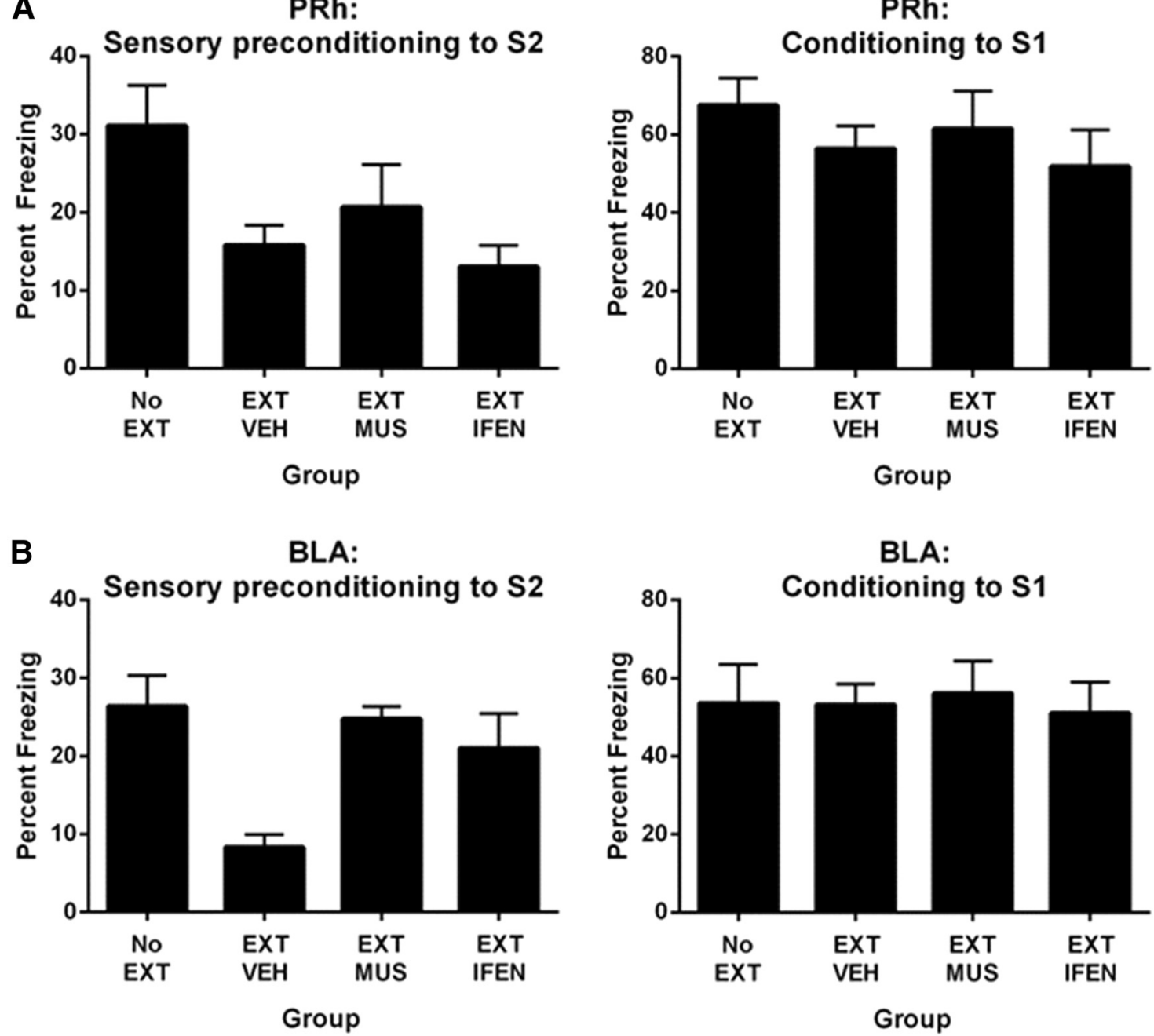

Figure 5. The roles of the PRh and BLA in extinction of sensory preconditioned fear. A, Extinction of sensory preconditioned fear does not require activation of the PRh or NMDAR in the PRh (Experiment 4A: EXT-MUS, $n=8$; EXT-IFEN, $n=8$; EXT-VEH, $n=8$; NO-EXT, $n=7$ ). Left, Freezing to S2 during the test for extinction of sensory preconditioned fear. Right, Freezing to $S 1$ during the test for retention of first-order conditioned fear. $\boldsymbol{B}$, Extinction of sensory preconditioned fear requires activation of the BLA and NMDAR in the BLA (Experiment 4B: EXT-MUS, $n=8$; EXT-IFEN, $n=8$; EXT-VEH, $n=9$; NO-EXT, $n=9$ ). Left, Freezing to S2 during the test for extinction of sensory preconditioned fear. Right, Freezing to 51 during the test for retention of first-order conditioned fear. Data shown are means \pm SEM.

Groups EXT-VEH and EXT-IFEN $\left(F_{(1,22)}=13.12 ; p<0.05\right)$, who did not differ from each other $\left(F_{(1,22)}=2.43 ; p>0.05\right)$. Figure $5 B$ shows test levels of freezing (mean \pm SEM) to S2 (Fig. $5 B$, left) and $\mathrm{S} 1$ (Fig. $5 B$, right). Extinction of sensory preconditioned fear was successful: Group NO-EXT froze significantly more to S2 than the other three groups combined $\left(F_{(1,30)}=5.39\right.$; $p<0.05)$. Muscimol or ifenprodil infusion into the BLA impaired extinction of sensory preconditioning freezing: rats in Groups EXT-MUS and EXT-IFEN did not differ in their levels of freezing to $\mathrm{S} 2\left(F_{(1,30)}<1 ; p>0.05\right)$, but these levels were significantly less than those by rats in Group EXT-VEH $\left(F_{(1,30)}=\right.$ $14.39 ; p<0.05)$. In the test of $S 1$, a mechanical failure of the DVD caused the loss of data from four rats (two rats from the EXTVEH Group, one rat from the EXT-MUS Group, and one rat from the EXT-IFEN Group). Analysis of the data from the remaining rats showed that infusion of muscimol or ifenprodil before extinction of the sensory preconditioned S2 had no effect on retention of first-order conditioned fear as there were no statistically significant differences among the groups in the test levels of freezing to $S 1\left(F_{(1,26)}\right.$ values $\left.<1 ; p>0.05\right)$.

Together with our previous findings, these results show that the roles of the PRh and BLA in the extinction of an association between S2 and S1 are also doubly dissociable depending on the value of S1: the PRh supports extinction when S1 is neutral but not when it has been conditioned; and the BLA supports extinction when S1 has been conditioned but not when it is neutral (Parkes and Westbrook, 2010).

Experiment 5A: demonstration of sensory preconditioned fear in a dangerous context

The protocols used in the previous experiments exposed rats to S1-US pairings and then S2-S1 pairings, or to S2-S1 pairings and then to S1-US pairings. The rats in each of these protocols thus differed in their history: the former rats had been subjected to fear 
Table 3. Behavioral demonstration of sensory preconditioning in a dangerous context

\begin{tabular}{llllll}
\hline & CXT cond & SPC & First-order & S2 test & S1 test \\
\hline Group PP & CXT - US & S2 - S1 & S1-US & S2- & S1- \\
Group PU & CXT - US & S2-S1 & S1/US & S2- & S1- \\
Group UP & CXT - US & S2/S1 & S1-US & S2- & S1- \\
\hline
\end{tabular}

S1 and S2 were a tone and flashing light stimulus (counterbalanced), and the US was electric footshock. A minus sign $(-)$ between two events denotes that the events were paired; a virgule (/) denotes that the two events were explicitly unpaired; a minus sign (-) following one event denotes that the event was presented alone (in the absence of shock). SPC, Sensory preconditioning; CXT cond, context conditioning.

conditioning before they received the S2-S1 pairings, whereas the latter rats had not been subjected to such a history. The remaining experiments examine the brain regions that code associations between S2 and a neutral S1 but in rats that had been previously subjected to fear conditioning, specifically, context fear conditioning.

The aim of Experiment 5A was to show that paired presentations of S2 and a neutral S1 result in sensory preconditioned fear of S2 when the pairings occurred in a dangerous context. The design is shown in Table 3. On Days 1 and 2, rats were exposed to the chambers. On Day 3, they were placed in the chambers for 5 min and shocked twice, after 3 and $4 \mathrm{~min}$. Each shock was $0.5 \mathrm{~mA}$ of $0.5 \mathrm{~s}$ duration. Three hours later, rats in Groups PP and PU received paired presentations of S2 and S1, whereas those in Group UP received unpaired presentations of S2 and S1. On Day 4, rats in Groups PP and UP received paired presentations of S1 and the US, whereas those in Group PU received unpaired presentations of S1 and the US. On Day 5, rats received a context extinction session in the morning and a second extinction session in the afternoon. On Days 6 and 7, rats were tested with S2 and S1, respectively, in the manner described previously.

None of the rats froze in the context before the shocks on Day 3 , and all of them froze after the shocks. Freezing increased linearly across exposure to the context $\left(F_{(1,24)}=155.07 ; p<0.05\right)$, but there were no differences among the groups $\left(F_{(1,24)}\right.$ values $<1.81 ; p>0.05)$, and the group $\times$ linear trend interactions were not significant $\left(F_{(1,24)}\right.$ values $\left.<2.33 ; p>0.05\right)$. Freezing declined linearly across exposure to the context in the afternoon session in which S2 and S1 were presented $\left(F_{(1,24)}=16.18 ; p<0.05\right)$, but there were no differences among the groups $\left(F_{(1,24)}\right.$ values $<2.31$; $p>0.05)$, and the group $\times$ linear trend interactions were not significant $\left(F_{(1,24)}\right.$ values $\left.<1 ; p>0.05\right)$.

First-order conditioning on Day 4 was successful. Freezing increased linearly across the four S1-shock pairings $\left(F_{(1,24)}=\right.$ $30.38 ; p<0.05)$. Groups PP and UP froze more to S1 than Group $\mathrm{PU}$, but this difference only approached significance $\left(F_{(1,24)}=\right.$ $4.01 ; p<0.06$ ), probably because the shocks interacted with the previous context conditioning to increase freezing levels among all rats. The linear $\times$ group interactions were not significant $\left(F_{(1,24)}\right.$ values $\left.<3.09 ; p>0.05\right)$. The mean $( \pm$ SEM) levels of freezing on the final S1 presentation were $53 \pm 10 \%$ in Group PP, $50 \pm 11 \%$ in Group UP, and $22 \pm 11 \%$ in Group PU. Figure $6 A$ shows test levels (mean \pm SEM) of freezing to S2 (Fig. 6A, left) and S1 (Fig. 6A, right). Group PP froze significantly more to S2 than Groups PU and UP $\left(F_{(1,24)}=15.81 ; p<0.05\right)$, but freezing in the latter groups did not differ $(F$ values $<1)$. Finally, Group PU froze less to $S 1$ than Groups PP and UP combined $\left(F_{(1,24)}=\right.$ $11.84 ; p<0.05)$, but freezing in the latter groups did not differ $(F$ values $<1)$. These results show that pairings of S2 and the neutral $S 1$ in a dangerous context followed by pairings of $S 1$ and shock resulted in sensory preconditioned fear of S2.

\section{Experiment 5B: in a dangerous context, the association} between $S 2$ and a neutral $S 1$ requires the BLA but not the PRh Experiment $5 \mathrm{~B}$ examined the roles of the PRh and BLA in the formation of an association between S2 and a neutral S1 in a dangerous context. Rats were implanted with cannulae targeting the PRh or BLA in both hemispheres and were allowed $7 \mathrm{~d}$ for recovery. The procedure was that used for Group PP in Experiment 5A. All rats received context exposure on Days 1 and 2, context conditioning in the morning session of Day 3, and S2-S1 pairings in the afternoon session. Twenty minutes before the afternoon session, half of the PRh rats and half of the BLA rats received an infusion of muscimol, while the remaining rats received an infusion of saline. All rats received pairings of S1-US on Day 4, and context extinction in the morning and afternoon of Day 5. Rats were tested with S2 on Day 6 and S1 on Day 7.

\section{Histology}

Three rats were excluded due to misplaced cannulae, yielding the following group sizes: BLA-VEH, $n=5$; BLA-MUS, $n=8$; PRh$\mathrm{VEH}, n=5$; and PRh-MUS, $n=7$.

\section{Behavior}

As there were no differences between PRh and BLA rats infused with saline at any stage of the experiment, the data for these rats were combined to form a single control group. All rats acquired fear to the context during the morning session of Day 3, in which they were placed in the context and shocked $\left(F_{(1,22)}=148.77 ; p<0.05\right)$. There was no overall difference between the groups $(F$ values $<1)$ and no group $\times$ linear trend interaction $(F$ values $<1)$. During the afternoon session in which S2 was paired with S1, Group VEH froze more than Groups PRh-MUS and BLA-MUS combined $\left(F_{(1,22)}=32.75\right.$; $p<0.05)$, and the latter groups did not differ $\left(F_{(1,22)}=1.98\right.$; $p>0.05)$. There was a linear decline in freezing across the session $\left(F_{(1,22)}=11.97 ; p<0.05\right)$, but the linear $\times$ group interactions were not significant $\left(F_{(1,22)}\right.$ values $\left.<2.34 ; p>0.05\right)$.

First-order conditioning was successful. The rate of acquisition of first-order fear did not differ between groups $\left(F_{(1,22)}\right.$ values $<1 ; p>0.05)$. The mean ( $\pm \mathrm{SEM}$ ) levels of freezing on the final S1 $\rightarrow$ shock trial were $50 \pm 7 \%$ in Group VEH, $51 \pm 0 \%$ in Group PRh-MUS, and $58 \pm 9.6 \%$ in Group BLA-MUS. Figure $6 B$ shows test levels (mean \pm SEM) of freezing to S2 (Fig. 6B, left) and S2 (Fig. 6B, right). Group BLA-MUS froze significantly less to S2 than Groups VEH and PRh-MUS $\left(F_{(1,22)}=4.89 ; p<0.05\right)$, and the latter groups did not differ from each other $\left(F_{(1,22)}<1\right.$; $p>0.05)$. In contrast, there were no differences between the groups in freezing to $S 1$ at test $\left(F_{(1,22)}<2.1 ; p>0.05\right)$. Thus, inactivation of the BLA impaired formation of an association between S2 and a neutral S1 in the dangerous context, and this effect was not due differences in conditioning of S1.

Two additional groups were used to examine whether NMDAR transmission in the BLA was critical for the plasticity underlying the association between S2 and a neutral S1 in the dangerous context. The protocol was identical to that described above except that S2-S1 pairings were conducted under a BLA infusion of ifenprodil (Group IFEN) or vehicle (Group VEH). One rat was excluded due to a misplaced cannula, resulting in eight rats in Group VEH and seven rats in Group IFEN.

Rats acquired fear in response to the context during the morning session of Day 3 in which they were placed in the context and shocked $\left(F_{(1,13)}=64.93 ; p<0.05\right)$. There was no difference between the groups $(F$ values $<1)$ and no group $\times$ linear trend interaction $(F$ values $<1)$. In the afternoon session in which S2 was paired with $\mathrm{S} 1$, context freezing declined linearly across the 


\section{$\mathbf{A}$}

Sensory preconditioning to S2

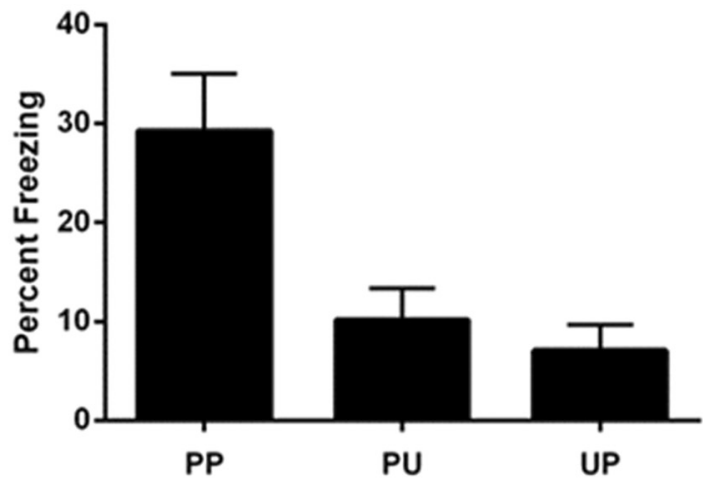

Group

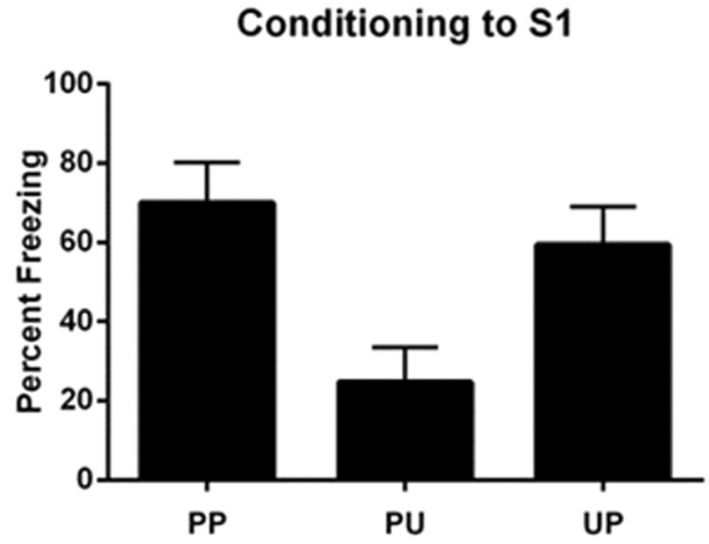

Group

CXT-US $\longrightarrow \uparrow_{\text {infusion }}^{\mathrm{S2} 2 \mathrm{S1}}$

B Sensory preconditioning to $\mathrm{S} 2$

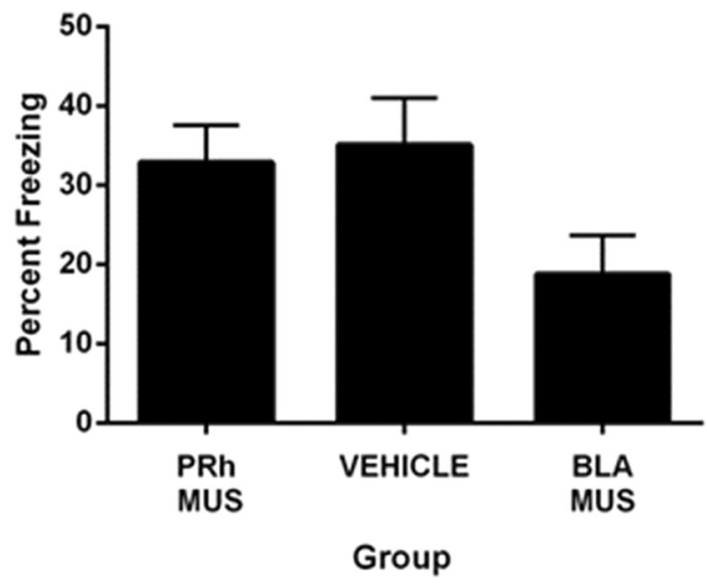

C Sensory preconditioning to S2

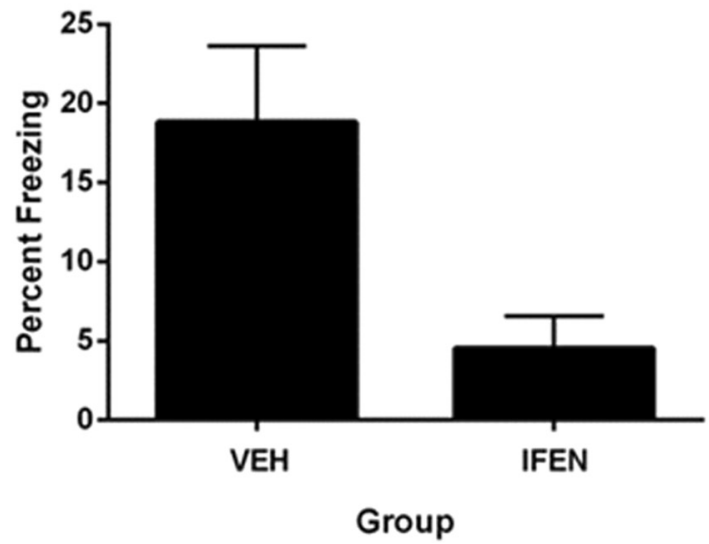

S1-US

S2-

s1-

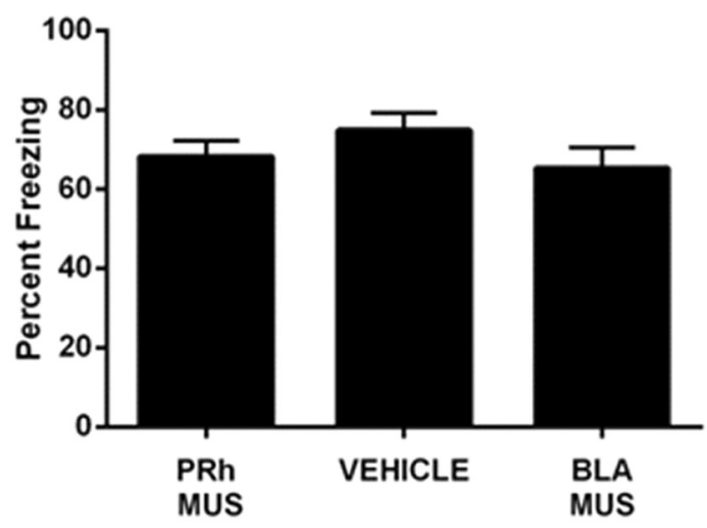

Group

\section{Conditioning to $\mathrm{S} 1$}

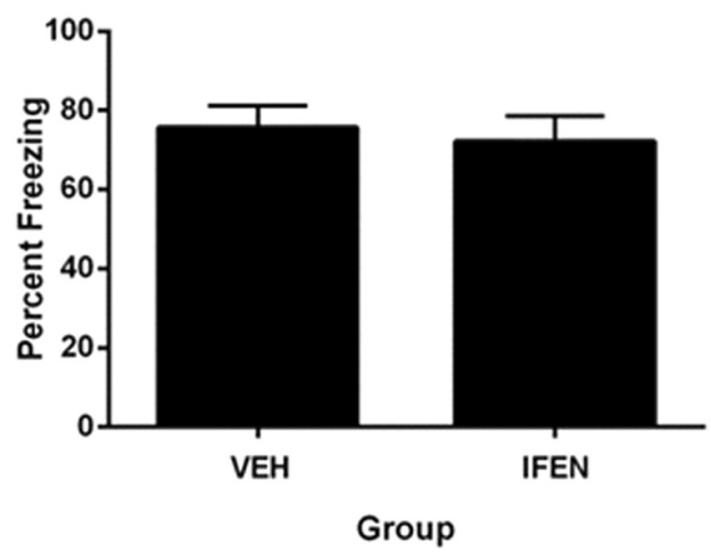

Figure 6. Sensory preconditioning in a dangerous context. $\boldsymbol{A}$, Behavioral demonstration of acquisition of a sensory preconditioned association in a dangerous context (Experiment $5 \mathrm{~A}$ : Group PP, $n=9$; Group PU, $n=8$; Group UP, $n=8$ ). Left, Freezing to $S 2$ during the test for sensory preconditioning. Right, Freezing to $S 1$ during the test for first-order conditioned fear. Data shown are means \pm SEM. $B$, Acquisition of a sensory preconditioned association in a dangerous context requires activation of the BLA but not the PRh (Experiment $5 B$ : BLA-MUS, $n=8 ;$ VEH, $n=10 ;$ PRh-MUS, $n=7)$. Left, Freezing to $S 2$ during the test for sensory preconditioning. Right, Freezing to $\mathbf{S 1}$ during the test for first-order conditioned fear. $C$, Acquisition of a sensory preconditioned association in a dangerous context requires activation of NMDAR in the BLA (Experiment $5 \mathrm{C}$ : Group VEH, $n=8$, Group IFEN, $n=7$ ). Left, Freezing to S2 during the test for sensory preconditioning. Right, Freezing to $S 1$ during the test for first-order conditioned fear. Data shown are means \pm SEM. 


\title{
CXT-US $\rightarrow$ S2-S1 $\rightarrow$ S2- or CXT only $\rightarrow$ S1-US $\rightarrow$ S2- $\rightarrow$ S1-
}

\author{
infusion
}

Sensory preconditioning to S2

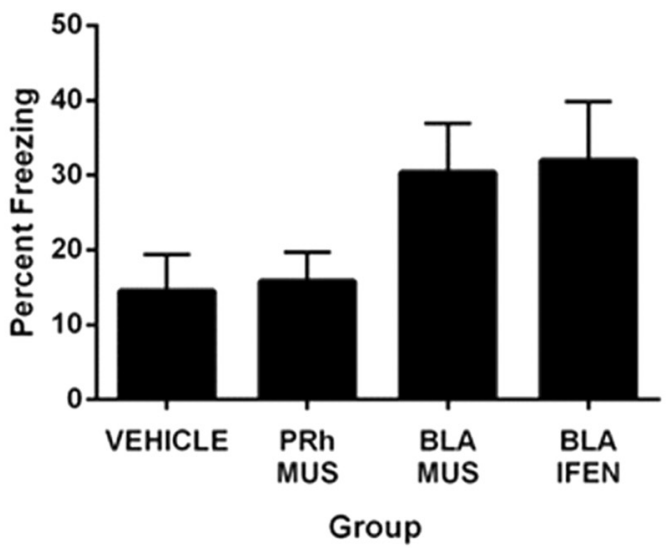

Conditioning to S1

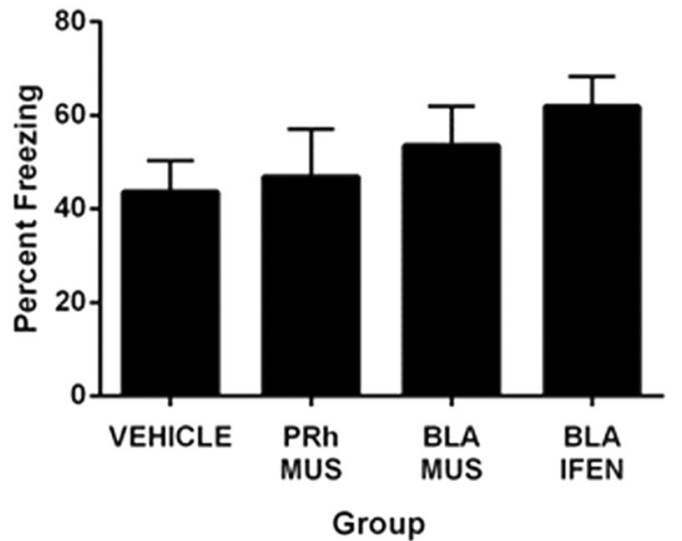

Figure 7. Pre-extinction of a sensory preconditioned association in a dangerous context requires activation of the BLA but not the PRh, and activation of NMDAR in the BLA (Experiment 6 : VEH, $n=12 ;$ PRh-MUS, $n=8 ;$ BLA-MUS, $n=8$; BLA-IFEN, $n=7$ ). Left, Freezing to S2 during the test for sensory preconditioning. Right, Freezing to $S 1$ during the test for first-order conditioned fear. Data shown are means \pm SEM.

session $\left(F_{(1,13)}=68.84 ; p<0.05\right)$, but the overall effect of group $(F$ values $<1)$ and the group $\times$ linear trend interaction $(F$ values $<1$ ) were not significant.

First-order conditioning was successful. The rate of acquisition of fear to S1 did not differ among groups $\left(F_{(1,13)}<1.03\right.$; $p>0.05)$. The mean ( \pm SEM) levels of freezing in the final S1-US trial were $75 \pm 10 \%$ in Group VEH and $89 \pm 9 \%$ in Group IFEN. Figure $6 C$ shows test levels (mean \pm SEM) of freezing to S2 (Fig. $6 C$, left) and S1 (Fig. $6 C$, right). Group VEH froze significantly more to S2 than Group IFEN $\left(F_{(1,13)}=6.64 ; p<0.05\right)$, showing that, in a dangerous context, NMDAR neurotransmission in the BLA is required for formation of an association between S2 and a neutral S1. The difference in freezing to S2 was not due to differences in first-order conditioning, as levels of freezing to S1 did not differ between groups ( $F$ values $<1)$. Together with the earlier results, these findings show that the roles of the PRh and BLA in the formation of an association between S2 and S1 are doubly dissociable depending on the value of the training context: the PRh supports associative formation in a safe or neutral context but not in a dangerous one; in contrast, the BLA supports associative formation in a dangerous context but not in a neutral one.

Experiment 6: in a dangerous context, extinction of an association between $S 2$ and a neutral $S 1$ requires NMDAR neurotransmission in the BLA but does not require the PRh Experiment 6 examined the roles of the PRh and BLA in the extinction of an association between S2 and a neutral S1 in a dangerous context. Rats in this experiment were surgically prepared and trained in the manner described for Experiment 5B. Specifically, rats received $2 \mathrm{~d}$ of context exposure, context conditioning in the morning of Day 3 followed by S2-S1 pairings in the afternoon. On Day 4, some of the PRh rats received an infusion of muscimol, while the remaining rats received an infusion of saline; some of the BLA rats received an infusion of muscimol, others received an infusion of ifenprodil, and the remaining rats received an infusion of vehicle. Twenty minutes after the infusion, rats were placed in the conditioning chambers, where they were exposed to eight presentations of S2 alone. Subsequent to first-order conditioning on Day 5 and two sessions of context extinction on Day 6, rats were tested with S2 on Day 7 and with S1 on Day 8.

Four rats were excluded from Experiment 6 due to misplaced cannulae. As there were no differences between PRh and BLA rats infused with vehicle at any stage of the experiment, the data for these rats were combined to form a single control group. Group sizes were as follows: VEH, $n=12$; PRh-MUS, $n=8$; BLA-MUS, $n=8$; and BLA-IFEN, $n=7$.

During the 5 min session of context conditioning on the morning of Day 3 , there was a linear increase in freezing $\left(F_{(1,32)}=\right.$ $112.02 ; p<0.05)$, but no differences between the groups $\left(F_{(1,32)}\right.$ values $<1.40 ; p>0.05)$ or group $\times$ linear trend interactions $\left(F_{(1,32)}<1.00 ; p>0.05\right)$. Freezing to the context declined across the afternoon session in which S2 was paired with S1. All rats initially showed a moderate level of freezing at the start of the session and little freezing at the end of the session $\left(F_{(1,32)}=69.65\right.$; $p<0.05)$. There was no difference in context freezing between Groups VEH and PRh-MUS $\left(F_{(1,32)}=2.05 ; p>0.05\right)$, or between Groups BLA-MUS and BLA-IFEN $(F$ values $<1)$. There was no difference in context freezing between the former and latter groups $(F$ values $<1)$ and no significant group $\times$ linear trend interactions $\left(F_{(1,32)}\right.$ values $\left.<1.10 ; p>0.05\right)$. There was also freezing to the context on Day 4 when S2 was presented alone. This freezing declined across the session $\left(F_{(1,32)}=17.46 ; p<0.05\right)$. There were no statistically significant differences between the groups in the levels of freezing to the context $\left(F_{(1,32)}\right.$ values $<1.93$; $\left.p>0.05\right)$, and the group $\times$ linear interactions were not significant $\left(F_{(1,32)}\right.$ values $<2.64$; $p>0.05$ ).

First-order conditioning was successful. The rate of acquisition of first-order fear did not differ between groups $\left(F_{(1,32)}\right.$ values $<1.69 ; p>0.05)$. The mean ( \pm SEM) levels of freezing on the final S1 $\rightarrow$ shock trial were $65 \pm 8.0 \%$ in Group VEH, $63 \pm 7.0 \%$ in Group PRh-MUS, $75 \pm 8 . \%$ in Group BLA-MUS, and $69 \pm$ $11 \%$ in Group BLA-IFEN. Figure 7 shows test levels (mean \pm SEM) of freezing to S2 (Fig. 7, left) and S1 (Fig. 7, right). Groups BLA-MUS and BLA-IFEN froze significantly more to S2 than 
Groups VEH and PRh-MUS $\left(F_{(1,32)}=7.18 ; p<0.05\right)$. There were no significant differences in the levels of freezing to $S 2$ between Groups BLA-MUS and BLA-IFEN $(F$ values $<1)$ or between Group VEH and PRh-MUS $(F$ values $<1)$. There were no differences between the groups in freezing to $S 1\left(F_{(1,32)}\right.$ values $<1.23$; $p>0.05$ ).

These results stand in contrast to those obtained earlier: in a safe or neutral context, the extinction of an association between $\mathrm{S} 2$ and S1 required neuronal activity in the PRh, specifically, NMDAR neurotransmission; neuronal activity in the BLA is not required for the extinction of the S2-S1 association under these circumstances (Parkes and Westbrook, 2010). However, in a dangerous context, the extinction of the S2-S1 association requires neuronal activity in the BLA, specifically, NMDAR neurotransmission; neuronal activity in the $\mathrm{PRh}$ is not required for extinction under these circumstances.

\section{Discussion}

\section{Recapitulation of the key results}

This series of experiments studied the roles of the PRh and BLA in sensory preconditioned and second-order conditioned fear. The initial experiments demonstrated that neuronal activity in the PRh, specifically NMDAR neurotransmission, is critical for the association between S2 and the neutral S1 (Experiment 1B). These findings confirm results observed in rats with lesions of the PRh (Nicholson and Freeman, 2000), while additionally showing that the PRh is critical for associative formation rather than updating of the association across the S1-US pairings or retrieval of the association at test. In addition, this study has demonstrated for the first time that plasticity in the PRh is critical for the extinction of the association between S2 and the neutral S1 (Experiment 2). The PRh, but not the BLA (Parkes and Westbrook, 2010), is thus critical for the formation and extinction of the association between S2 and the neutral S1. In contrast, the BLA, but not the PRh, is critical not only for the association between S2 and the conditioned S1 (Experiment 3B), but also for the extinction of the fear responses elicited by the second-order or the sensory preconditioned S2 (but see Parkes and Westbrook, 2010; Experiment $4 \mathrm{~B}$ ). The present experiments confirmed this role for the BLA in the extinction of the fear responses elicited by the sensory preconditioned S2 and additionally demonstrated that the $\mathrm{PRh}$ is not involved in the extinction of this fear (Experiment 4A).

These results show that the brain regions coding the associations produced by paired presentations of S2 and S1 are determined by the emotional significance of S1: the BLA, but not the $\mathrm{PRh}$, is critical for the association between S2 and a fear-eliciting $\mathrm{S} 1$, whereas the PRh, but not the BLA, is critical for the association between S2 and a neutral S1. Similarly, the brain regions that code the extinction of the associations between S2 and S1 are determined by the emotional significance of S2: the BLA, not the $\mathrm{PRh}$, is critical for the extinction of the fear elicited by S2 (either second-order conditioned or sensory preconditioned), whereas the PRh, but not the BLA, is critical for extinction of the association between $\mathrm{S} 2$ and the neutral $\mathrm{S} 1$.

However, these conclusions regarding the roles of the PRh and BLA in forming and extinguishing associations between S2 and a neutral S1 only apply in a familiar, safe context. In a dangerous context, neuronal activity, specifically, NMDAR neurotransmission in the BLA, but not in the PRh, is critical for the association between S2 and a neutral S1 (Experiment 5B) as well as extinction of this association when S2 was presented in the absence of its neutral S1 associate (Experiment 6). Consequently, the roles of the PRh and BLA are again doubly dissociable with respect to acquisition and extinction of a neutral stimulus-stimulus association. Specifically, the roles of these structures in forming and extinguishing associations between S2 and a neutral S1 depend on the emotional significance of the context. In a safe context, the $\mathrm{PRh}$, not the BLA is critical. However, in a dangerous context the PRh ceases to support associative formation. Instead, sensory representations of the paired auditory and visual stimuli converge in the BLA, where the formation and extinction of their association is encoded via NMDAR-mediated plasticity.

\section{Interactions between the PRh and BLA}

These findings raise two questions. The first is how the neutral S2-S1 association stored in the PRh results in expression of sensory preconditioned fear. Here, it is worth noting that expression of sensory preconditioned fear was impaired by muscimolinduced activation of both the PRh (Experiment 4A) and BLA (Experiment 4B). This suggests that activation of both brain regions is critical for expression of this fear. One possibility is that the PRh-mediated S2-S1 association makes contact with the BLA-mediated S1-US association. In this respect, there are strong reciprocal (glutamatergic) connections between the BLA and PRh (Shi and Cassell, 1999; Pitkanen et al., 2000); and other evidence shows that, under some circumstances, these brain areas interact in the service of motivated behavior (Paz et al., 2006, 2009; Bauer et al., 2007).

The second question is why the PRh does not compensate when the BLA is inactivated during second-order conditioning. To be sure, inactivation of the BLA eliminates fear responses, and, hence, S2 could not have associated with the fear elicited by S1 (there was none). Here, the PRh could have been recruited to encode the association between the sensory properties of S2 and S1, effectively transforming second-order conditioning into sensory preconditioning. However, no such compensation was observed: second-order fear conditioning to $\mathrm{S} 2$ was clearly impaired by inactivation of the BLA but was completely spared following inactivation of the PRh. One possibility is that, when activated, the BLA provides positive feedback to the thalamus, such that subsequent presentations of paired auditory and visual stimuli are processed in the BLA and not the PRh. Hence, the BLA mediates the formation and extinction of associations between a neutral stimulus and a learned danger signal, or between neutral stimuli in a dangerous environment; and critically, when the BLA is inactivated, the PRh does not compensate because the thalamus continues to route signals to the BLA and not the PRh.

\section{The PRh and BLA are part of distinct neural pathways}

Although the PRh and BLA interact under some circumstances, the fact that an association between innocuous stimuli can be processed in either the PRh or the BLA, depending on a subject's emotional state, suggests that these brain areas are also parts of distinct neural pathways. In this respect, several studies have examined the anatomical properties of pathways connecting the thalamus to structures in the medial temporal lobe (including the $\mathrm{PRh}$ and BLA) and their functional significance for auditory fear conditioning (Li et al., 1996; Weisskopf and LeDoux, 1999; Doron and Ledoux, 2000; Yaniv et al., 2000, 2001; Doyère et al., 2003; Sigurosson et al., 2010). These studies have identified two critical pathways: the first is a cortical pathway in which information is transmitted from specific thalamic nuclei (the dorsal and ventral medial geniculate) to the lateral and basolateral amygdala via primary auditory cortex and PRh; the second is a subcortical pathway from other thalamic nuclei (medial geniculate body, posterior intralaminar nucleus, and suprageniculate nucleus) to 
the lateral amygdala (LeDoux, 2003, 2007). It has been suggested that these two pathways have distinct roles in stimulus processing. Activation of the indirect (and therefore, slower) cortical pathway has been implicated in detailed processing of stimulus attributes (LeDoux, 2007; Sigurosson et al., 2010); thus, plasticity in this pathway may support the formation of an association between the sensory features of paired stimuli. In contrast, activation of the direct (and therefore, fast) subcortical pathway has been linked to rapid initiation of defensive reactions to danger (LeDoux, 2007; Sigurosson et al., 2010). Plasticity in this pathway may be necessary for learning about the motivational relevance of paired stimuli.

One implication of the present findings is that motivational state can bias activation of one pathway over the other. In the absence of fear, cortical processing (involving the PRh) dominates and supports learning about the relationship between sensory features of paired stimuli; however, when a state of fear prevails, the subcortical pathway (involving the BLA) is activated to facilitate appraisal of the need for fight or flight, and, as a consequence, it takes over processing of the same relationships. In light of the proposed distinction between information content conveyed by thalamo-cortical (sensory) and thalamo-amygdala (affective, motivational) pathways, a further implication of fearinduced activation of the latter may be a lower-resolution encoding of stimulus detail (Adolphs et al., 2001). This is relevant to anxiety disorders like post-traumatic stress, which have been associated with heightened arousal and amygdala hyperactivity (Goodman et al., 2012), as well as information-processing bias (Buckley et al., 2000; Weber, 2008) and specific deficits in episodic memory (Isaac et al., 2006). This suggests that encoding of general rather than specific detail in these disorders may occur as a consequence of the arousal or anxiety-induced transition from cortical to subcortical processing of the environment (Isaac et al., 2006). Impaired processing of detail may underlie enhanced generalization of fear and anxiety across a range of environmental stimuli reported in the context of these disorders (Kheirbek et al., 2012).

\section{Summary}

We have shown that how sensory stimuli are processed by the brain depends on an animal's emotional state at the time these stimuli are encountered. When the context is safe, sensory stimulation activates cortical pathways that permit detailed (or high-resolution) processing of stimulus attributes and their relations. However, when the context is dangerous (and thus, animals are in a state of fear), sensory stimulation bypasses the cortex and, instead, is routed directly to the amygdala so that responses relevant to the current motivational state can be quickly initiated. These findings support the view that thalamo-amygdala and thalamo-cortical pathways process functionally distinct aspects of stimuli and their relations. Pathological activation of these pathways may underpin aberrations in stimulus processing that characterize many psychopathological conditions, including clinical anxiety.

\section{References}

Adolphs R, Denburg NL, Tranel D (2001) The amygdala's role in long-term declarative memory for gist and detail. Behav Neurosci 115:983-992. CrossRef Medline

Bauer EP, Paz R, Paré D (2007) Gamma oscillations coordinate amygdalorhinal interactions during learning. J Neurosci 27:9369-9379. CrossRef Medline

Buckley TC, Blanchard EB, Neill WT (2000) Information processing and PTSD: a review of the empirical literature. Clin Psychol Rev 20:1041-1065. CrossRef Medline

Coppock WJ (1958) Pre-extinction in sensory preconditioning. J Exp Psychol 55:213-219. CrossRef Medline
Doron NN, Ledoux JE (2000) Cells in the posterior thalamus project to both amygdala and temporal cortex: a quantitative retrograde double-labeling study in the rat. J Comp Neurol 425:257-274. CrossRef Medline

Doyère V, Schafe GE, Sigurdsson T, LeDoux JE (2003) Long-term potentiation in freely moving rats reveals asymmetries in thalamic and cortical inputs to the lateral amygdala. Eur J Neurosci 17:2703-2715. CrossRef Medline

Fanselow MS (1980) Conditioned and unconditional components of postshock freezing. Pavlov J Biol Sci 15:177-182. Medline

Gewirtz JC, Davis M (1997) Second-order fear conditioning prevented by blocking NMDA receptors in amygdala. Nature 388:471-474. CrossRef Medline

Goodman J, Leong KC, Packard MG (2012) Emotional modulation of multiple memory systems: implications for the neurobiology of posttraumatic stress disorder. Rev Neurosci 23:627-643. CrossRef Medline

Hays WL (1963) Statistics for psychologists. New York: Holt, Rinehart and Winston.

Herry C, Ciocchi S, Senn V, Demmou L, Müller C, Lüthi A (2008) Switching on and off fear by distinct neuronal circuits. Nature 454:600-606. CrossRef Medline

Isaac CL, Cushway D, Jones GV (2006) Is posttraumatic stress disorder associated with specific deficits in episodic memory? Clin Psychol Rev 26: 939-955. CrossRef Medline

Kheirbek MA, Klemenhagen KC, Sahay A, Hen R (2012) Neurogenesis and generalization: a new approach to stratify and treat anxiety disorders. Nat Neurosci 15:1613-1620. CrossRef Medline

LeDoux J (2003) The emotional brain, fear, and the amygdala. Cell Mol Neurobiol 23:727-738. CrossRef Medline

LeDoux J (2007) The amygdala. Curr Biol 17:R868-R874. CrossRef Medline

Li XF, Stutzmann GE, LeDoux JE (1996) Convergent but temporally separated inputs to lateral amygdala neurons from the auditory thalamus and auditory cortex use different postsynaptic receptors: in vivo intracellular and extracellular recordings in fear conditioning pathways. Learn Mem 3:229-242. CrossRef Medline

Nicholson DA, Freeman JH Jr (2000) Lesions of the perirhinal cortex impair sensory preconditioning in rats. Behav Brain Res 112:69-75. CrossRef Medline

Parkes SL, Westbrook RF (2010) The basolateral amygdala is critical for the acquisition and extinction of associations between a neutral stimulus and a learned danger signal but not between two neutral stimuli. J Neurosci 30:12608-12618. CrossRef Medline

Paxinos G, Watson C (1997) The rat brain in stereotaxic coordinates, Ed 3. San Diego: Academic.

Paz R, Pelletier JG, Bauer EP, Paré D (2006) Emotional enhancement of memory via amygdala-driven facilitation of rhinal interactions. Nat Neurosci 9:1321-1329. CrossRef Medline

Paz R, Bauer EP, Paré D (2009) Measuring correlations and interactions among four simultaneously recorded brain regions during learning. J Neurophysiol 101:2507-2515. CrossRef Medline

Pitkanen A, Pikkarainen M, Nurminen N, Ylinen A (2000) Reciprocal connections between the amygdala and the hippocampal formation, perirhinal cortex, and postrhinal cortex in rat. A review. Ann N Y Acad Sci 911:369-391. CrossRef Medline

Rodrigues SM, Schafe GE, LeDoux JE (2001) Intra-amygdala blockade of the NR2B subunit of the NMDA receptor disrupts the acquisition but not the expression of fear conditioning. J Neurosci 21:6889-6896. Medline

Shi CJ, Cassell MD (1999) Perirhinal cortex projections to the amygdaloid complex and hippocampal formation in the rat. J Comp Neurol 406: 299-328. CrossRef Medline

Sigurosson T, Cain CK, Doyere V, LeDoux JE (2010) Asymmetries in longterm and short-term plasticity at thalamic and cortical inputs to the amygdala in vivo. The Eur J Neurosci 31:250-262. CrossRef

Sotres-Bayon F, Bush DE, LeDoux JE (2007) Acquisition of fear extinction requires activation of NR2B-containing NMDA receptors in the lateral amygdala. Neuropsychopharmacology 32:1929-1940. CrossRef Medline

Weber DL (2008) Information processing bias in post-traumatic stress disorder. Open Neuroimag J 2:29-51. CrossRef Medline

Weisskopf MG, LeDoux JE (1999) Distinct populations of NMDA receptors at subcortical and cortical inputs to principal cells of the lateral amygdala. J Neurophysiol 81:930-934. Medline

Wilensky AE, Schafe GE, LeDoux JE (1999) Functional inactivation of the 
amygdala before but not after auditory fear conditioning prevents memory formation. J Neurosci 19:RC48. Medline

Yaniv D, Schafe GE, LeDoux JE, Richter-Levin G (2000) Perirhinal cortex and thalamic stimulation induces LTP in different areas of the amygdala. Ann N Y Acad Sci 911:474-476. CrossRef Medline
Yaniv D, Schafe GE, LeDoux JE, Richter-Levin G (2001) A gradient of plasticity in the amygdala revealed by cortical and subcortical stimulation, in vivo. Neuroscience 106:613-620. CrossRef Medline 